\title{
RESEARCH
}

Open Access

\section{Microglial and peripheral immune priming is partially sexually dimorphic in adolescent mouse offspring exposed to maternal high- fat diet}

Maude Bordeleau ${ }^{1,2,3}$, Chloé Lacabanne ${ }^{1}$, Lourdes Fernández de Cossín ${ }^{4}$, Nathalie Vernoux ${ }^{2}$, Julie C. Savage ${ }^{2,5}$, Fernando González-Ibáñez ${ }^{2,5}$ and Marie-Ėve Tremblay $2,5,6,7,8^{*}$ (D)

\begin{abstract}
Background: Maternal nutrition is critical for proper fetal development. While increased nutrient intake is essential during pregnancy, an excessive consumption of certain nutrients, like fat, can lead to long-lasting detrimental consequences on the offspring. Animal work investigating the consequences of maternal high-fat diet (mHFD) revealed in the offspring a maternal immune activation (MIA) phenotype associated with increased inflammatory signals. This inflammation was proposed as one of the mechanisms causing neuronal circuit dysfunction, notably in the hippocampus, by altering the brain-resident macrophages-microglia. However, the understanding of mechanisms linking inflammation and microglial activities to pathological brain development remains limited. We hypothesized that mHFD-induced inflammation could prime microglia by altering their specific gene expression signature, population density, and/or functions.

Methods: We used an integrative approach combining molecular (i.e., multiplex-ELISA, rt-qPCR) and cellular (i.e., histochemistry, electron microscopy) techniques to investigate the effects of mHFD (saturated and unsaturated fats) vs control diet on inflammatory priming, as well as microglial transcriptomic signature, density, distribution, morphology, and ultrastructure in mice. These analyses were performed on the mothers and/or their adolescent offspring at postnatal day 30 .

(Continued on next page)
\end{abstract}

\footnotetext{
* Correspondence: evetremblay@uvic.ca

${ }^{2}$ Axe neurosciences, Centre de recherche du CHU de Québec-Université Laval, Québec, QC, Canada

${ }^{5}$ Département de médecine moléculaire, Université Laval, Québec, QC, Canada

Full list of author information is available at the end of the article
}

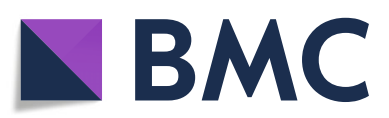

(- The Author(s). 2020 Open Access This article is licensed under a Creative Commons Attribution 4.0 International License, which permits use, sharing, adaptation, distribution and reproduction in any medium or format, as long as you give appropriate credit to the original author(s) and the source, provide a link to the Creative Commons licence, and indicate if changes were made. The images or other third party material in this article are included in the article's Creative Commons licence, unless indicated otherwise in a credit line to the material. If material is not included in the article's Creative Commons licence and your intended use is not permitted by statutory regulation or exceeds the permitted use, you will need to obtain permission directly from the copyright holder. To view a copy of this licence, visit http://creativecommons.org/licenses/by/4.0/ The Creative Commons Public Domain Dedication waiver (http://creativecommons.org/publicdomain/zero/1.0/) applies to the data made available in this article, unless otherwise stated in a credit line to the data. 
(Continued from previous page)

Results: Our study revealed that mHFD results in MIA defined by increased circulating levels of interleukin (IL)-6 in the mothers. This phenotype was associated with an exacerbated inflammatory response to peripheral lipopolysaccharide in mHFD-exposed offspring of both sexes. Microglial morphology was also altered, and there were increased microglial interactions with astrocytes in the hippocampus CA1 of mHFD-exposed male offspring, as well as decreased microglia-associated extracellular space pockets in the same region of mHFD-exposed offspring of the two sexes. A decreased mRNA expression of the inflammatory-regulating cytokine Tgfb1 and microglial receptors Tmem119, Trem2, and Cx3 $\mathrm{Cr} 1$ was additionally measured in the hippocampus of mHFD-exposed offspring, especially in males.

Conclusions: Here, we described how dietary habits during pregnancy and nurturing, particularly the consumption of an enriched fat diet, can influence peripheral immune priming in the offspring. We also found that microglia are affected in terms of gene expression signature, morphology, and interactions with the hippocampal parenchyma, in a partially sexually dimorphic manner, which may contribute to the adverse neurodevelopmental outcomes on the offspring.

Keywords: Hippocampus, Immune priming, Maternal high-fat diet, Microglia, Sex difference

\section{Background}

Maternal obesity and dietary overconsumption are risk factors for several health conditions in the offspring, from metabolic syndrome to neurodevelopmental disorders [1-3]. In fact, excess weight has been on the rise in both middle and high income countries, affecting over one third of the global population and about 38.9 million pregnant women worldwide [4]. This increase in the number of overweight or obese pregnant women has been linked to several elements of modern-day environment such as urbanization rate and increased caloric supply [4], which are often associated with increased fast food consumption [5]. This global issue stresses the importance of studying the impact of energy-dense, highsugar, and high-fat food diets during pregnancy [5].

Providing high-fat diet (HFD) to animal models mimics the excessive intake of energy-dense, high-sugar, and high-fat food in human [6]. Of these overconsumed nutrients, fat is of utmost importance for brain growth and development [7]. However, several independent studies using different animal models of maternal (m)HFD have shown a broad range of lasting behavioral alterations in the offspring related to neurodevelopmental disorders from increased anxiety-like behaviors [8-13] to cognitive [8, 14-18], social, and motor deficits [9]. Although the mechanisms linking mHFD to the neurodevelopmental alterations remain unclear, several pathological processes such as decreased placental function, hormonal dysregulation, epigenetic alterations [2], and increased central as well as systemic inflammation [1] have been proposed.

In the past decade, epidemiological studies identified "maternal immune activation" (MIA), which refers to maternal systemic inflammation, as a risk factor for several neurodevelopmental disorders [19-22]. This has mostly been observed and researched in the context of infection, where a tight association between bacterial or viral (e.g., influenza) infections during pregnancy and a higher incidence of neurodevelopmental disorders, such as schizophrenia, was uncovered in the progeny $[19,20$, 23]. It is now known that MIA is not limited to infection $[19,20,23]$ and may occur after exposure to a large variety of maternal environmental risk factors common to modern-day life including stress [24, 25], smoking, alcohol consumption [26], air pollution [27, 28], and dietary imbalance or overconsumption such as HFD [1]. Postmortem studies revealed neuroimmune alterations in the brain of individuals with developmental disorders, as highlighted by the alteration of microglia-the brainresident macrophages, in terms of morphology and gene expression signature [29-31], together with changes in the brain levels of cytokines-the molecules involved in signalling and modulation of the inflammatory state, among other important functions [19, 20, 23].

In animal models of mHFD, the inflammatory status in the offspring brain, notably in hippocampus, has been characterized by measuring changes of several inflammatory mediators during the lifespan. The mRNA expressions of Cd11b and Tlr4-two genes involved in the innate immune response-were found to be increased in the hippocampus of male and female rat offspring as early as postnatal day (PND)1, followed by interleukin (Il) $1 \beta$ at juvenile stages [8]. During adolescence, both male and female rat offspring exhibited greater levels of the cytokine Il6, as well as of the inflammatory regulators nuclear factor $\kappa b(N f \kappa b)$ and mitogen-activated kinase protein $(M k p) 1$ in the hippocampus [32]. Adolescent male rat offspring also expressed increased levels of $N f_{\kappa} b$ inhibitor $\left(I_{\kappa} B\right)$ in the hippocampus. Later in adult life, a few studies observed no change in cytokines [10] while others found greater expression of $I l 1 \beta$ in the hippocampus of male rats [8], and lower expression of $I K B$ and Ill ra in the hippocampus of female rats 
[13] exposed to mHFD. However, it remains unclear if this increased gene expression of inflammatory mediators is directly linked to a global inflammatory status or to altered microglial activities in the offspring brain. So far, the reported microglial changes induced by mHFD in the offspring brain comprise a higher density of ionized calcium-binding adapter 1 (IBA1)positive $\left(^{+}\right)$cells in the hippocampus of adult male and female rats [8] suggesting changes in microglial population or recruitment of peripheral macrophages to the brain.

Studies performed in animal models and human postmortem samples have revealed that microglia modulate key neurodevelopmental processes-cell migration and maturation, followed by the formation of neuronal circuits and myelination-in a sexually dimorphic manner [33-35]. Microglia also contribute to neuronal circuit refinement during adolescence [36] and adulthood [29, 35, 37-39]. Paralleling the immune alterations described above, mHFD was shown to be associated with synaptic changes resulting in decreased synapses density and/or spines density and stability in rodent offspring across brain regions and stages of the lifespan [16, 25, 40-42] including the hippocampus of adolescent mice [16]. Microglial cell density, distribution, gene expression signature, physiological functions, and/or response to immune challenges may be altered upon exposure to various environmental factors, thus impacting on their sculpting of the brain network [43, 44]. This phenomenon is referred to as immune priming [43-45]. Studying microglial priming during sensitive periods like adolescence, in which the brain and especially the hippocampus experience important synaptic changes, may help to understand the pathological cascade underlying mHFD.

Using a mouse model, we explored the changes of microglia in the offspring exposed to mHFD (enriched in both saturated and unsaturated fats) vs control diet (CD) [8]. Specifically, we investigated microglia-related gene expression in whole hippocampus, as well as microglial density, distribution, morphology, and ultrastructure in the dorsal hippocampus CA1. We focused on this region considering its crucial importance for memory, learning [46, 47], and executive [48] functions that are affected with MIA [19-22] including with mHFD $[8,15,16,42]$. The measurements were made at PND30, which corresponds to early adolescence [49]. To characterize our model, we also assessed metabolic changes in the mothers and offspring, together with peripheral immune priming in the adolescent offspring, using a single systemic immune challenge with lipopolysaccharide (LPS) at PND30. Male and female offspring were compared in all experiments to investigate possible sex differences.

\section{Methods}

\section{Animal and tissue processing}

All animal protocols were approved by McGill University's Facility Animal Care Committee under the guidelines of the Canadian Council on Animal Care. Mice were submitted to $12 \mathrm{~h}$ dark/light cycles (8:00-20:00) with an ad libitum access to water and food. A total of 116 females were used, and 50 females got pregnant after mating, out of which 16 lost their litter (e.g., spontaneous abortion in late pregnancy, cannibalism, leaked water bottle). A total of 112 offspring was used to study the effects of mHFD.

Paired-housed C57BL/6 N female mice aged 5-6 weeks were obtained from Charles River (St-Constant, QC, Canada) and habituated for 1 week prior to the protocol onset. They were then provided with either a HFD (diet rich in saturated [36\% of total fat] and unsaturated fats [monounsaturated $41 \%$ of total fat and polyunsaturated $23 \%$ of total fat], $60.3 \%$ calories from lipids [3.075 kcal/ g], $18.3 \%$ calories from proteins $[0.933 \mathrm{kcal} / \mathrm{g}]$, and $21.4 \%$ calories from carbohydrates $[1.091 \mathrm{kcal} / \mathrm{g}]$; Teklad TD.06414, ENVIGO, Indianapolis, IN, USA; Supplementary Figure 1 e) or CD (13\% calories from lipids [0.377 $\mathrm{kcal} / \mathrm{g}$ ] composed of saturated [17.6\% of total fat] and unsaturated fats [monounsaturated $20.6 \%$ of total fat and polyunsaturated $61.8 \%$ of total fat], $20 \%$ calories from proteins $[0.580 \mathrm{kcal} / \mathrm{g}]$, and $67 \%$ calories from carbohydrates [1.943 kcal/g]; Teklad 2014, ENVIGO; Supplementary Figure 1e) ad libitum starting 4 weeks prior to mating, throughout gestation and nurturing, until weaning of their litter (Fig. 1). After mating, pregnant female were housed alone, then with their litter. During the diet protocol, food consumption and weight were recorded twice per week in the dams to identify potential metabolic changes. Food consumption was averaged by number of animals housed and consumed food. About $4 \mathrm{~h}$ after their active phase with food ad libitum (between 12:00 and 13:00), blood samples were collected by submandibular puncture after 8 weeks on the diet to evaluate the inflammatory profile and assess circulating glucose levels. No fasting was performed since at that timepoint dams were also used either for cytokines assessment or fat distribution, and we did not want fasting to interact with these measures. Dams were anesthetized with a rodent cocktail $(0.3 \mathrm{~mL} / 100 \mathrm{~g})$ containing ketamine $[100 \mathrm{mg} / \mathrm{mL}]$, xylazine $[20 \mathrm{mg} / \mathrm{mL}]$, and aceprozamine $[10 \mathrm{mg} / \mathrm{mL}]$, fresh-decapitated at the end of the protocol, after 9-10 weeks on the diet, and their fat deposits were dissected (Fig. 1).

Male and female offspring were compared to study mHFD effects in the two sexes. During the study, animals presenting major anomalies (e.g., unopened or abnormal eye, dwarf or severe tooth malformation) were excluded from the experimental groups and sacrificed at 


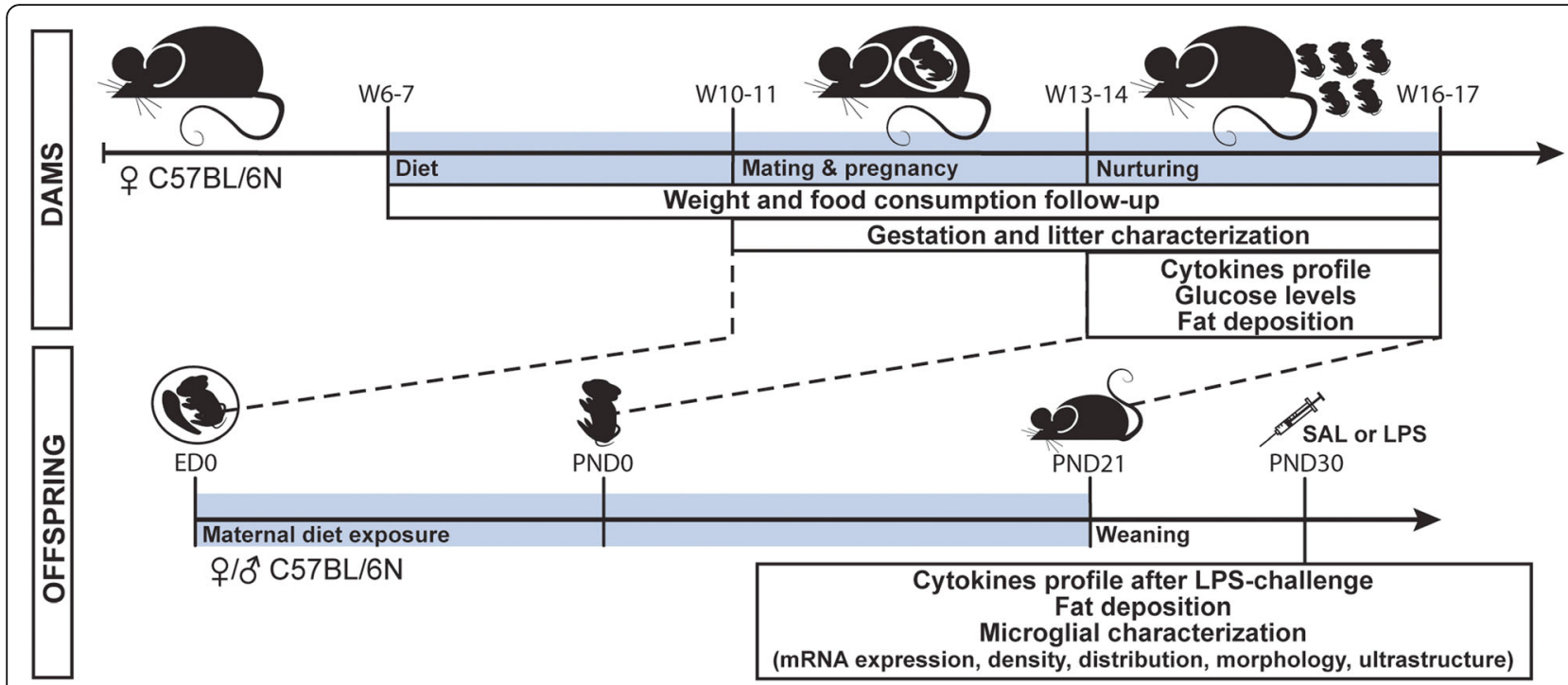

Fig. 1 Experimental outline of HFD protocol on the dams and the offspring. Diet protocol period is identified by a pale blue-colored bar on the dams and the offspring timelines. At PND21, all offspring were on normal chow diet before sacrifice at PND30. Part of the animals received an intraperitoneal LPS injection $8 \mathrm{~h}$ before characterizing their peripheral inflammatory profile. 9 , female; 0 , male; $\mathrm{E}$, embryonic days; LPS, lipopolysaccharide; P, postnatal days; SAL, saline; W, weeks

weaning. Only 1-2 offspring of each sex per litter were used for each experiment to prevent litter effects. At PND21, the offspring were weaned and switched to CD. Offspring from same litter were housed together (2 to 5 animals due to animal housing restriction and birthtimed limitations) with sufficient resources (food, water, nesting) to prevent any competitive behavior. Of note, offspring's weight gain between weaning and PND30 was similar regardless of the housing number. At PND30, offspring were anesthetized with rodent cocktail, and their blood, brain, and fat tissues were collected. One cohort of offspring ( $n=5-6 \mathrm{animal} / \mathrm{sex} / \mathrm{diet}$ ) was fresh-decapitated, their brain rapidly extracted, and the hippocampus dissected, flash-frozen on dry ice, and stored at $-80^{\circ} \mathrm{C}$ until mRNA analysis by real-time quantitative polymerase chain reaction (rt-qPCR). Another cohort of offspring was anesthetised as described above, perfused with $15 \mathrm{~mL}$ of phosphate-buffered saline (PBS) followed by $180 \mathrm{~mL}$ of $4 \%$ paraformaldehyde (PFA) in $[50 \mathrm{mM}]$ phosphate-buffer (PB) for histological analysis ( $n=5$ animals/sex/diet). PFA-fixed brains were post-fixed in $4 \%$ PFA for $24 \mathrm{~h}$ at $4{ }^{\circ} \mathrm{C}$, then immersed in $30 \%$ glucose solution (in $[50 \mathrm{mM}] \mathrm{PBS}$ ), $\mathrm{pH}=7.4$ ) at $4{ }^{\circ} \mathrm{C}$ for $48 \mathrm{~h}$ and flash-frozen. Frozen brains were cut into $30 \mu \mathrm{m}$ coronal sections using a cryostat (CM3050S, Leica Biosystems, Wetzlar, Germany) and stored freefloating in cryoprotectant (30\% ethylene glycol, $30 \%$ glycerol in $[50 \mathrm{mM}] \mathrm{PBS}, \mathrm{pH}=7.4)$ at $-20^{\circ} \mathrm{C}$ until use for histochemistry. The last cohort of animals was anesthetised as described above, flushed with $15 \mathrm{~mL}$ of PBS, and perfused with $75 \mathrm{~mL}$ of $3.5 \%$ acrolein in $[100 \mathrm{mM}] \mathrm{PB}$
$(\mathrm{pH}=7.4)$ and $150 \mathrm{~mL}$ of $4 \%$ PFA in $[100 \mathrm{mM}] \mathrm{PB}(\mathrm{pH}$ $=7.4)$ for ultrastructural analysis $(n=4$ animals $/ \mathrm{sex} /$ diet). PFA/acrolein-fixed brains were post-fixed for $2 \mathrm{~h}$ in $4 \%$ PFA at $4{ }^{\circ} \mathrm{C}$, washed in PBS, cut into $50 \mu \mathrm{m}$ coronal sections with a vibratome (VT1200S, Leica Biosystems), and stored in cryoprotectant solution at $-20^{\circ} \mathrm{C}$ until use (Fig. 1).

\section{Adolescent peripheral immune challenge}

To evaluate peripheral immune priming, a subset of animals ( $n=5-7$ animals/sex/diet/treatment) received a single intraperitoneal injection at PND30, of either $100 \mu \mathrm{g} / \mathrm{kg}$ lipopolysaccharide (LPS) from Escherichia coli O111:B4 (cat\# 62325, Millipore Sigma, Burlington, MA, USA) - a component of the gram-negative bacterial wall used to model an inflammatory response-or saline (SAL; 0.9\% $\mathrm{NaCl}$ solution, cat\# 01966010, Hospira, USA). Eight hours after the administration, animals were anesthetized with rodent cocktail $(0.3 \mathrm{~mL} / 100 \mathrm{~g})$ and decapitated. This timepoint corresponds to the resolution of inflammation after the peak usually seen $\sim 2-4 \mathrm{~h}$ in the periphery and $\sim 4-6 \mathrm{~h}$ in adult mouse brain [50-53]. Trunk blood was collected in heparinized tubes and centrifuged at $3600 \mathrm{rpm}$ for $10 \mathrm{~min}$. Plasma was collected and flash-frozen and stored at $-80^{\circ} \mathrm{C}$ until analysis by multiplex-ELISA (see section "Cytokines measurement by multiplex-ELISA”) (Fig. 1).

\section{Physiological changes}

To determine the phenotype induced by our diet model, a thorough characterization of the gestation and litter, as 
well as metabolic changes including weight, food intake, fat distribution, and glucose levels was performed in the dams. The methods and results are presented as Supplementary material.

\section{Cytokines measurement by multiplex-ELISA}

To determine changes in the inflammatory profile of the dams, peripheral inflammation was assessed at the end of nurturing (after 8-9 weeks on the diet) $(n=5-6$ dams/diet). Similarly, the peripheral inflammatory profile of the pubertal offspring (PND30) was characterized in homeostatic (SAL-treated) vs immune (LPS-treated) contexts $(n=5-6$ animals/sex/diet/treatment). Levels of the cytokines IL-1 $\beta$, IL-6, IL-10, IL-17, and tumor necrosis factor (TNF)- $\alpha$ were measured in maternal and offspring plasma using Luminex Multiplex Assay (MILLIP LEX MAP kit Mouse Cytokine/Chemokine Magnetic Bead Panel, cat\# MCYTOMAG-70 K, Millipore Sigma). Plasma samples were diluted $1: 2$ by combining $30 \mu \mathrm{L}$ of plasma with the provided drive fluid buffer. Immunoassays were performed following the manufacturer's instructions. Diluted plasma was incubated overnight ( $16 \mathrm{~h}$ ) with primary antibodies at $4{ }^{\circ} \mathrm{C}, 1 \mathrm{~h}$ with detection antibodies at room temperature, and $30 \mathrm{~min}$ with Streptavidin-beads at room temperature. Samples were resuspended in $150 \mu \mathrm{L}$ drive fluid and run through the Luminex MAGPIX to assess cytokines levels with the xPONENT software (v4.2.1324.0). Acquisition was done using manufacturer's recommendation for the volumeuptake of sample $(100 \mu \mathrm{L})$, the gate setting (8000-15, 000), and the reporter gain (default, low PMT).

\section{Real-time quantitative polymerase chain-reaction}

At PND30, the two hippocampi of each offspring ( $n=5-6$ animals/sex/diet) were homogenized in Trizol (cat\#15596026, Ambion, Austin, TX, USA), and RNA was extracted using the Trizol/chloroform method followed by an isopropanol precipitation. The RNA pellet was washed once in $75 \%$ ethanol, let dry, then eluted in Nuclease-free water (cat\#AM9937, Ambion). Samples were dosed using the NanoDrop ND-1000 kit (ThermoFisher Scientific).

Genomic DNA was removed from $1 \mu \mathrm{g}$ isolated RNA sample by enzymatic degradation (cat\# G488, Applied Biological Materials Inc, Richmond, BC, Canada). Purified RNA was used to obtain complementary DNA (cDNA) by reverse transcriptase reaction with iScript $5 \times$ MasterMix (cat\#1708890, BioRad Laboratories, Hercules, CA, USA) using a TI thermocycler (Biometra, Göttingen, Germany). Using optimal dilution of cDNA, rt-qPCR was performed with the SybrGreen technology using a LightCycler 480 II (Roche, Basel, Switzerland). The LightCycler 480 Software (v.1.5.1.62; Roche) automatically determined cycle threshold $(\mathrm{Ct})$ as the linear portion of the amplification, as suggested per manufacturer's guidelines. After each rt-qPCR, melting curve analysis was used to confirm proper amplification of a unique target.

Rt-qPCR was used to measure downstream inflammatory mediators $N f_{k} b$ and Cox2 (after $8 \mathrm{~h}$ LPS-induced immune challenge), microglial function-related genes Tmem119, Aif1, Trem2, Cx3cr1, homeostatic-regulating factor $T g f b 1$ as well as housekeeping genes Rpl32 and Gapdh (primers detailed in Table 1). For each gene's primer pairs, dilution standard curve with a pool sample (1: $1,1: 5,1: 25,1: 125,1: 625,1: 3125 ; 1: 15,625)$ was used to determine optimal dilution cDNA (from $1 \mu \mathrm{g}$ RNA reverse transcriptase reaction), and melt curve analysis was used to confirm specificity of the primer pairs. Rpl32 obtained more stable Ct (intersample, $0.33 \% \mathrm{CV}$; intrasample, $0.29 \% \mathrm{CV}$ ) compared to Gapdh (intersample, $3.7 \% \mathrm{CV}$; intrasample, $0.42 \% \mathrm{CV}$ ); hence, it was used to calculate the relative expression of target genes. Relative expression was calculated by determining the difference of $\mathrm{Ct}$ between the genes of interest and the housekeeping gene $\left(2^{-\Delta \Delta C t}\right)$, while arbitrarily considering CDexposed male offspring as the reference group [54]. Results were presented in ratio fold, and statistical analysis was assessed on $\Delta \Delta \mathrm{Ct}$ which are normally distributed.

Other than the cytokine $T g f b 1$, we attempted to assess mRNA levels of $I l 1 b$ and $I l 6$; however, we failed to obtain robust amplification by rt-qPCR during the primer design phase.

\section{Microglial density, distribution, and morphology analysis} PFA-perfused brain sections were double-immunostained against IBA1 (labels all myeloid cells including microglia) and transmembrane protein 119 (TMEM119; microgliaspecific [55]) to evaluate microglial density, distribution, and morphology, as well as myeloid cell infiltration as previously described [56]. Three to four brain sections containing the dorsal hippocampus CA1 (Bregma, - 1.31 to 1.91; stereotaxic atlas of Paxinos and Franklin 4th edition [57]) were selected for each offspring ( $n=5$ animals/sex/ diet). Sections were washed, incubated $40 \mathrm{~min}$ in sodium citrate buffer to expose epitopes, washed again and treated with $0.1 \% \mathrm{NaBH}_{4}$ (cat\#480886, MilliporeSigma) to quench autofluorescence. Afterwards, brain sections were incubated in blocking solution $(0.5 \%$ gelatin, $5 \%$ donkey serum, $0.1 \%$ Triton $\mathrm{X}-100$ ) for $1 \mathrm{~h}$ at room temperature, washed and incubated overnight at $4{ }^{\circ} \mathrm{C}$ with a cocktail of monoclonal primary antibodies in blocking solution: mouse anti-IBA1 (1:190; cat\# MABN92, Millipore Sigma) and rabbit anti-TMEM119 (1:300; cat\# ab209064, Abcam). The sections were washed and incubated with the polyclonal secondary antibodies donkey anti-mouse Alexa555conjugated (1:300 in PBS; cat\#A31570, Invitrogen, ThermoFisher Scientific) and donkey anti-rabbit Alexa647conjugated (1:300 in PBS; cat\#A31573, Invitrogen, ThermoFisher Scientific) for $1.5 \mathrm{~h}$ at room temperature. 
Table 1 Primers sequence for rt-qPCR experiments

\begin{tabular}{|c|c|c|}
\hline Targets & Primer 5' & Primer 3' \\
\hline$N f k b$ & CAC CTA GCT GCC AAA GAA GG & GCA GGC TAT TGC TCA TCA CA \\
\hline $\operatorname{Cox} 2$ & TGF TGG TGG AAA AAC CTC GT & GGT GCT CGG CTT CCA GTA TT \\
\hline Tmem119 & TTC TTC CGG CAG TAC GTG AT & CGA GGA TGG GTA GTA GGC TG \\
\hline Aif1 & TCT GCC GTC CAA ACT TGA AG & GCC ACT GGA CAC CTC TCT AA \\
\hline Trem2 & ACC CTC TAG ATG ACC AAG ATG C & TTG GGC ACC CTC GAA ACT C \\
\hline$C \times 3 c r 1$ & CAA GCT CAC GAC TGC CTT CT & TGT CCG GTT GTT CAT GGA GTT \\
\hline$T g f b 1$ & ACA TGT GGA ACT CTA CCA GAA A & CTG CCG TAC AAC TCC AGT GA \\
\hline Rpl32 & TTG TTG CTC CCA TAA CCG ATG & TTA AGC GAA ACT GGC GGA AAC \\
\hline Gapdh & GGA GAA ACC TGC CAA GTA TGA & GGT CCT CAG TGT AGC CCA AG \\
\hline
\end{tabular}

Aif1 allograft inflammatory factor 1, Cox2 cyclooxygenase 2, Cx3cr1 fractalkine receptor, Gapdh glyceraldehyde 3-phosphate dehydrogenase, Nf $k$ b nuclear factor kappa B, Tgfb1 transforming growth factor $\beta 1$, Tmem 119 transmembrane protein 119 , Trem2 triggering receptor expressed by myeloid cells 2

Sections were then mounted on slides and coverslipped in Fluoromount mounting medium (cat\# 0100-01, SouthernBiotech, Birmingham, AB, USA).

For density and distribution analysis, all stained sections were imaged in a single plane mosaic at $\times 20$ using an Axio Imager M2 epifluorescence microscope equipped with an AxioCam MRm camera and acquired with the Zen Pro 2012 software (Zeiss, Oberkochen, Germany). For morphology analysis, z-stacks (stratum radiatum (st rad), 18-20 z-stacks/animal; stratum lacunosum moleculare (st lac mol), 10-15 z-stacks/animal) were captured at $\times 40$ using a Quorum Wave FX spinning disc confocal microscope (Quorum Technologies, Guelph, ON, Canada) equipped with an ORCA-R2 camera $(512 \times 512$ pixels; Hamamatsu Photonics, Hamamatsu, Japan). The z-stacks were merged into a single plane using the Volocity software (Version 5.4, PerkinElmer, Waltham, MA, USA).

All analyses were performed blind to the experimental condition using the ImageJ software (v1.51j8; National Institute of Health, Bethesda, MD, USA). Total count of $\mathrm{IBA}^{+} / \mathrm{TMEM} 19^{+}$(microglia) and $\mathrm{IBA}^{+} / \mathrm{TMEM} 19^{-}$ (peripheral macrophages) cells was compiled for the dorsal hippocampus CA1, st rad and st lac mol, across 6-8 hippocampi per animal, using the analyze particles plugin $[56,58]$. Afterwards, cellular distribution was assessed using the nearest neighbor distance (NDD) plugin. For microglial morphology analysis, the number of branches and junctions, as well as average and longest branch length, was obtained (st rad: $n=20-25$ microglia/animal, st lac mol: $n=15-20$ microglia/animal, $n=5$ animals/sex/ diet) using a semi-automatic method adapted from [59]. For each microglial cell, soma and manual arbor were also traced using the freehand tool and polygon selection tool to obtain area values. Morphological index for each microglia was calculated by dividing the soma area by the manual arborization area to help identify microglial changes from their steady state [56, 58]. Manual arbor selection was further processed in a semi-automated manner to obtain unsharp mask of the cell, adjusted by the observer when needed, and area of the cell as well as shape descriptor (i.e., circularity, solidity, and aspect ratio) values were measured. Circularity was calculated by $4 \pi \times($ area/perimeter $^{2}$ ), for which a value of 1.0 represents a perfect circle and towards 0.0 an elongated shape. Solidity was calculated by dividing the cell area by the convex cell area meaning that a value close to 0.0 indicates a porous shape and close to 1.0 a convex shape. Finally, the aspect ratio was calculated by dividing the major axis of the cell by the minor axis of the cell, meaning a value of 1.0 similar ratio of minor and major axis and the higher the value the more elongated the cell is. The mask of the cell was skeletonized and analyzed using skeleton 2D/3D plugin. Skeleton analysis allowed us to determine number, average length, and maximal length of branches as well as number of junctions.

\section{Microglial ultrastructure analysis}

Two PFA/acrolein-perfused brain sections containing the dorsal hippocampus CA1 (Bregma - $1.67 \mathrm{~mm}$; stereotaxic atlas of Paxinos and Franklin 4th edition [57]) were selected in each of four animals per group. Sections were washed in PBS, then quenched $10 \mathrm{~min}$ in $0.3 \% \mathrm{H}_{2} \mathrm{O}_{2}$ in PBS and permeabilized $30 \mathrm{~min}$ in $0.1 \% \mathrm{NaBH}_{4}$ in PBS. Sections were first incubated $1 \mathrm{~h}$ at room temperature in blocking solution ( $10 \%$ fetal bovine serum, $3 \%$ bovine serum albumin, $0.01 \%$ Triton $\mathrm{X}-100$ in $[50 \mathrm{mM}]$ trisbuffered saline (TBS)). Afterwards, sections were incubated overnight at $4^{\circ} \mathrm{C}$ with rabbit anti-IBA1 polyclonal primary antibody (1:1000; cat\#019-19741, FUJIFILM Wako Chemical, Osaka, Japan) in blocking solution. The following day, antibody was washed out, and the sections were incubated with biotinylated goat anti-rabbit polyclonal secondary antibody (cat\# 111-066-046, Jackson ImmunoResearch, West Grove, PA, USA) in TBS for 1.5 $\mathrm{h}$, followed by avidin-biotin complex solution (1:1:100 in TBS; cat\# PK-6100, Vector Laboratories, Burlingame, CA, USA) for $1 \mathrm{~h}$ at room temperature. The staining was revealed in $0.05 \%$ diaminobenzidine (DAB; cat\# D5905- 
50TAB, Millipore Sigma) with $0.015 \% \mathrm{H}_{2} \mathrm{O}_{2}$ in TBS for $4.5 \mathrm{~min}$ at room temperature.

The immunostained sections were next post-fixed flat in osmium-thiocarbohydrazide-osmium for scanning electron microscopy (SEM). In particular, sections were incubated in 3\% ferrocyanide (cat\# PFC232.250, BioShop, Burlington, ON, Canada) diluted in water combined (1:1) with 4\% aqueous osmium tetroxide (cat\#19170, Electron Microscopy Sciences, Hatfield, PA, USA) for $1 \mathrm{~h}$, in $1 \%$ thiocarbohydrazide diluted in water (cat\# 2231-57-4, Electron Microscopy Sciences) for 20 min, in $2 \%$ osmium tetroxide diluted in water, then dehydrated in ascending concentration of ethanol $(2 \times$ $35 \%, 50 \%, 70 \%, 80 \%, 90 \%, 3 \times 100 \%$ ) followed by propylene oxide $(3 \times)$ for $5 \mathrm{~min}$ each. After post-fixation, tissues were embedded in Durcupan ACM resin (cat\# 4461144614, Millipore Sigma) for $24 \mathrm{~h}$ and carefully placed between two ACLAR ${ }^{\circ}$ embedding films (cat\# 50425-25, Electron Microscopy Sciences), and the resin was let to polymerize at $55^{\circ} \mathrm{C}$ for $72 \mathrm{~h}$. Regions of selection-dorsal hippocampus $\mathrm{CA} 1$-were excised from the embedded sections on ACLAR ${ }^{\circ}$ sheets and re-embedded on top of a resin block for ultrathin sectioning (Ultracut UC7 ultramicrotome, Leica Biosystems). Ultrathin sections ( $75 \mathrm{~nm}$ thickness) were collected and placed on a silicon nitride chip and glued on specimen mounts for SEM. Seven to 12 microglial cell bodies in each animal/layer of interest (st rad and st lac $\mathrm{mol}$ ) were imaged at $5 \mathrm{~nm}$ of resolution using a Crossbeam 540 field emission SEM with a Gemini column (Zeiss).

Ultrastructural analysis was performed blind to the experimental conditions using the ImageJ software (st rad: $n$ = 32-41 microglia/sex/diet, st lac mol: $n=28-36$ microglia/sex/diet, $n=4$ animals/sex/diet). Microglial endoplasmic reticulum, Golgi apparatus, lysosomes, lipofuscin, mitochondria, and endosomes were first analyzed quantitatively [60]. Dilation of the endoplasmic reticulum and/or Golgi apparatus was noted when the distance between the cisternal membranes was $50 \mathrm{~nm}$ or greater [61, 62]. Lysosomes were identified by their dense heterogenous contents enclosed by a single membrane [63, 64]. Secondary lysosomes were differentiated from primary lysosomes by their contacts with fusion endosomes. Tertiary lysosomes were identified by their contacts with lipofuscin and often also with fusion endosomes $[63,65]$. Lipofuscin granules, for their part, were identified by their oval or round structure and finely granular composition with a unique fingerprint-like pattern [65]. Mitochondria were considered as elongated when their length was greater than $1 \mu \mathrm{m}$ [60]. Microglial contacts with the cell bodies from other brain cells (i.e., astrocytes, neurons, oligodendrocytes) as well as blood vessels were quantified. For the neurons, contacted myelinated axons and synaptic elements-presynaptic axon terminal or post-synaptic dendritic spine- were further identified. Astrocytic cells were identified by their pale nuclei with a thin rim of heterochromatin and pale irregular cytoplasm, often containing intermediary filaments [66]. Neurons were distinguished by their pale nuclei and pale cytoplasm, often with an apical dendrite and innervation from axon terminals [66]. Pre-synaptic axon terminals were differentiated by their synaptic vesicles, while post-synaptic spines were in contact with a presynaptic axon terminal, often with a visible post-synaptic density at their junction [66]. Microglia were recognized by their dark irregular nuclei with a heterogenous chromatin pattern and a dark irregular cytoplasm, often containing short endoplasmic reticulum cisternae and lipidic inclusions (i.e., lipofuscin, lipid bodies or droplets, lysosomes) [66]. Similar to microglia, oligodendrocytes were identified by their dark nuclei with a heterogenous chromatin pattern and dark squarish or rectangular-shape cytoplasm, often containing short and wide endoplasmic reticulum cisternae organised in the vicinity of the nucleus and ribosomes, as well as a wider space between nuclear membranes than microglia [66]. In the vicinity of microglia, the occurrence of degradation activities (degenerating myelin, extracellular digestion) was also noted. Extracellular digestion, also named "exophagy," was identified as extracellular space pockets containing degraded elements or debris $[67,68]$. In contrast, degenerating myelin was recognized by ballooning, swelling, or distancing of myelin sheaths [66].

In addition, the density of dark cells and apoptotic cells was assessed ( $n=4$ animals/sex/diet). Then, dark cells were analyzed in a semi-quantitative manner (st rad: $n=$ 0-6 dark cells/sex/diet, st lac mol: $n=13-19$ dark cells/ sex/diet, $n=4$ animals/sex/diet). Dark cells were distinguished by their electron-dense nuclei showing a loss of the chromatin pattern and electron-dense cytoplasm presenting several signs of cellular stress (i.e., dilated endoplasmic reticulum and Golgi apparatus cisternae, elongated mitochondria) [69]. In the present study, we distinguished between two types of dark cells: microglia and perivascular cells. In addition to their dark features, dark microglia were recognised by their microglial characteristics [60, 69] and were located inside the brain parenchyma. Dark perivascular cells were identified by their localization enclosed in the perivascular space and possessed the dark features mentioned above. Apoptotic cells were also dark and recognised with their pyknotic nucleus and accumulation of autophagic endosomes [70].

Sample size of dark cells in st lac mol ( $n=59$ individual dark cells total) was considered sufficient to attempt statistical data analysis. This assumption was based on the sample size calculated using the G*Power software (v3.1.9.6) [71] to detect a large effect size of 0.4 that was estimated to 52 individuals cells. 


\section{Statistical analyses}

Data are reported as means \pm standard error of the mean (SEM). Sample size (n) refers to individual animals for metabolic parameters, immune priming, gene expression as well as microglial density and morphology analyses, while it refers to individual microglia or dark cells for ultrastructural analyses. Statistical analyses were conducted using Prism 8 (v.8.3, GraphPad Software, San Diego, CA, USA). Normality was verified using ShapiroWilk and assessed by QQ plot. For normally distributed dataset, Grubbs' test (two-tailed, $\alpha=0.05$ ) was used to identify outliers that were removed from the datasets prior to performing parametric statistic tests. To compare CD vs HFD in the dams, a Student $t$ test was used for non-repeated measures including glucose levels, weight, and fat deposit measurements, while a 2-way analysis of variance (ANOVA) for repeated measures test was used for comparing weight and dietary followup data across time. In the offspring, a 2-way ANOVA was used to compare CD vs mHFD, as well as male and female animals for metabolic parameters (i.e., weight and fat deposits), gene expression, as well as microglial density, distribution, morphology, and ultrastructure. Significant ANOVA tests with a sex $\times$ diet interaction were followed by Bonferroni post-hoc test to identify significant differences between individual groups. For nonnormally distributed dataset, a Mann-Whitney test was used to compare CD vs HFD in the dams for cytokines profile, gestation duration, and litter size. For nonnormally distributed offspring dataset, a mixed-effect model was used to compare CD vs mHFD, males vs females in terms of myeloid cells infiltration, as well as to compare SAL vs LPS groups after immune challenge to assess cytokines profile. Significant mixed-effect model was followed by a Bonferroni post-hoc test. Statistically significant differences were considered for $p$ value $<0.05$.

\section{Results}

High-fat diet induces long-term increase of peripheral IL6 and fat deposits in dams and male offspring

HFD has been associated with a variety of metabolic changes including increased body fat, obesity, diabetic-like phenotype (glucose and/or insulin intolerance) [72], and decreased fertility [73]. To characterize further our model, we assessed weight and food consumption, glucose levels, fat deposits, as well as gestation duration and litter size in the dams. These measurements revealed that mHFD does not induce obesity, although it is associated with an overconsumption of fats to the detriment of carbohydrates (Supplementary Figure 1) and does not induce glycemia changes (Supplementary Figure 2 a). HFD nevertheless resulted in an increase of retroperitoneal, subcutaneous, and perigonadal fat deposition at the measured endpoint, without driving an overall increase of total body mass or an obese phenotype (Supplementary Figure $2 \mathrm{~b}-\mathrm{g}$ ). Importantly, it did not lead to fertility alterations, ruling out major metabolic alterations as often seen in diet-induced animal models of obesity (Supplementary Figure $2 \mathrm{~h}-\mathrm{k}$ ).

Studying offspring exposed to a mHFD revealed that they are more prone to developing metabolic syndrome, which includes increase in fat deposits and body weight [2]. In our study, mHFD offspring had similar body weight compared to $\mathrm{CD}$ offspring at PND30, but the mHFD males showed increased perigonadal fat deposits compared to CD males (Supplementary Figure 3), which highlights a sexually dimorphic effect of mHFD on offspring fat deposition.

Rodent models of mHFD were also previously shown to induce peripheral inflammation, notably by increasing the levels of cytokines in maternal blood circulation [14, $28,74,75]$. To evaluate the maternal immune profile in our mouse model of mHFD, we measured plasma levels of pro- (IL-1 $\beta$, IL-6, IL-17, TNF- $\alpha$ ) and antiinflammatory (IL-10) cytokines in the dams at weaning of their litter by multiplex-ELISA. Plasma levels of IL- 6 were significantly increased $\left(U=0, \mathrm{n}_{1}=\mathrm{n}_{2}=5, p=\right.$ $0.0079)$ in HFD-fed dams $(17.74 \pm 8.79 \mathrm{pg} / \mathrm{mL})$ compared to CD-fed dams $(3.636 \pm 0.933 \mathrm{pg} / \mathrm{mL}$ ) (Fig. $2 \mathrm{~d}$ ), while both diet groups had similar levels of IL-1 $\beta$, IL10, IL-17, and TNF- $\alpha$ (Fig. 2a-b, e). Overall, these results suggest a MIA phenotype induced by MHFD in our model, confirmed by the increase of IL-6.

mHFD offspring have higher IL-6 plasma levels after LPSinduced immune challenge, while hippocampal inflammatory response remained similar to CD-exposed offspring

To assess peripheral immune priming in the adolescent offspring, we measured circulating cytokines by multiplex ELISA at PND30, $8 \mathrm{~h}$ after systemic injection of low dose LPS vs SAL. This timepoint corresponds to a period of inflammatory resolution after the immune challenge in adult mouse brain, allowing us to evaluate prolonged inflammatory response [50-53]. In LPSinjected animals, plasma levels of IL-6 were significantly elevated $\left(F_{(1,37)}=10.44, p=0.0317\right)$ in mHFD vs CD offspring regardless of their sex $(436.8 \pm 107.0 \mathrm{pg} / \mathrm{mL}$ vs $197.9 \pm 74.1 \mathrm{pg} / \mathrm{mL}$ ) (Fig. 3a). Moreover, regardless of their maternal diet, LPS-treated female offspring had significantly $\left(F_{(1,37)}=5.324, p=0.0004\right)$ increased plasma levels of IL-6 compared to LPS-treated male offspring $(504.1 \pm 113.8 \mathrm{pg} / \mathrm{mL}$ vs $152.3 \pm 44.0 \mathrm{pg} / \mathrm{mL})$ (Fig. 3a). Levels of TNF- $\alpha$ and IL-10 were also significantly increased (TNF- $\alpha: F_{(1,37)}=16.43, p=0.0002$; IL-10: $F_{(1,21)}$ $=30.63, p<0.0001)$ in LPS-treated offspring compared to SAL-treated offspring regardless of their sex or maternal diet (TNF- $\alpha, 15.23 \pm 2.66 \mathrm{pg} / \mathrm{mL}$ vs $4.435 \pm 0.745$ $\mathrm{pg} / \mathrm{mL}$;L-10, $82.54 \pm 8.03 \mathrm{pg} / \mathrm{mL}$ vs $10.76 \pm 7.40 \mathrm{pg} /$ 


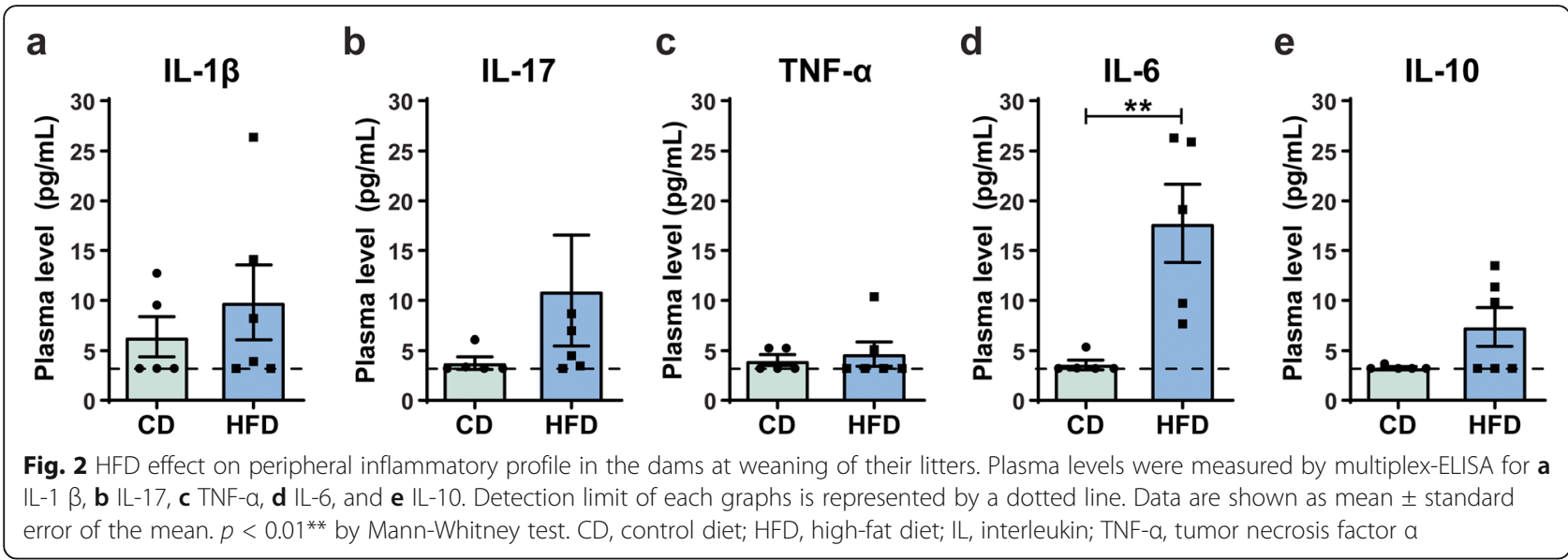

mL) (Fig. 3b-c, f). Finally, levels of IL-1 $\beta$ and IL-17 were similar between SAL-treated and LPS-treated offspring regardless of their sex and maternal diet (Fig. 3d-f). Together, these results indicate that systemic LPS administration induced IL-6, IL-10, and TNF- $\alpha$ release detected $8 \mathrm{~h}$ afterwards in CD and mHFD offspring, while IL-6 release was significantly exacerbated in mHFD offspring, indicating either a sustained inflammation or a stronger response to the immune challenge specific to this cytokine upon exposure to mHFD.

Similarly, we evaluated inflammatory response in the hippocampus by measuring mRNA transcript expression by $\mathrm{rt}-\mathrm{qPCR}$ of two genes downstream of proinflammatory cytokines during inflammation, $N f_{\kappa} b[76$, 77] and Cox2 [51], $8 \mathrm{~h}$ after administration of LPS or SAL. Upon LPS treatment, both CD- and mHFDexposed offspring showed significantly increased mRNA expression level of $N f k b$ (SAL, 0.711 vs LPS, 1.184 ratio fold; $F_{(1,37)}=5.646, p=0.0228$; detailed in Table 2; Fig. $3 \mathrm{~g})$ and Cox2 (SAL, 0.793 vs LPS, 1.200 ratio fold; $F_{(1,37)}$ $=7.608, p=0.0090$; detailed in Table 2; Fig. 3h). In the SAL condition, $N f k b$ level was decreased in mHFDexposed male offspring compared to other offspring groups $\left(F_{(1,37)}=5.344\right.$, SAL-CD male: $p=0.0044$, SALCD female: $p=0.0037$, SAL-mHFD female: $p=0.0002$; detailed in Table 2; Fig. 3g). Taken together, these results suggest that immune response of the hippocampus was similar with mHFD. However, $N f k b$ homeostatic functions (e.g., synaptic plasticity and regulation of neuronal excitability) [77] may be altered at steady-state in mHFD-exposed male offspring.

Male offspring have altered gene expression after mHFD whereas both male and female offspring exhibit altered microglial morphology

Other than a peripheral inflammatory response, immune priming has been associated with changes in gene expression and/or morphology of immune cells-including microglia in the brain $[1,28,78]$. To characterize microglia-related gene changes, we used rt-qPCR to study mRNA expression in whole hippocampus of mHFD vs CD offspring at PND30 (Fig. 4a). We focused on Tgfb1-a cytokine that modulates inflammation and microglia survival [79] - as well as on receptors mainly expressed by microglia in the brain that are involved with the regulation of inflammation (i.e., Aif1 [80]), microglial survival (i.e., Tmem119 [55], Trem2 [81]), or synaptic remodeling (i.e., Cx3cr1 [82-84], Trem2 [82, 85-87]). mHFD-exposed male offspring had significantly reduced expression of $\mathrm{Tg} f b 1\left(F_{(1,19)}=10.05, \mathrm{CD}\right.$ male: $p$ $=0.0045$, CD female: $p=0.0018$, mHFD female: $p=$ $0.0008)$ compared to other offspring groups (detailed in Table 2; Fig. 4b). Expression of Aif1 was however similar between groups (Fig. 4c). mHFD-exposed male offspring also had a significantly lower ratio fold of Tmem119 $\left(F_{(1,19)}=19.47\right.$, CD male: $p<0.0001$, CD female: $p<$ 0.0001 , mHFD female: $p<0.0001)$, Trem $2\left(F_{(1,19)}=\right.$ 20.88, CD male: $p<0.0001$, CD female: $p<0.0001$, mHFD female: $p<0.0001)$, and Cx3cr1 $\left(F_{(1,19)}=16.44\right.$, CD male: $p=0.0002$, CD female: $p<0.0001$, mHFD female: $p<0.0001)$ compared to the other offspring groups (detailed in Table 2; Fig. 4d-f). Together, these results indicate that mHFD leads to altered expression, specifically in males, of inflammatory-regulating (Tgfb1) as well as microglial function-related (Tmem119, Trem2, and $C \times 3 c r 1)$ genes.

After performing rt-qPCR, we characterized the density, distribution, morphology, and ultrastructure of microglia in mHFD vs CD-exposed offspring at PND30. We focused on the dorsal hippocampus CA1, particularly the st rad and st lac mol-two main layers where neuronal plasticity occurs during cognitive processes [88] and that are associated to behavioral deficits previously reported in mHFD animal models $[8,14-18]$. In both layers (Fig. $5 \mathrm{a}-\mathrm{e}, \mathrm{n}-\mathrm{r}$ ), the density and distribution

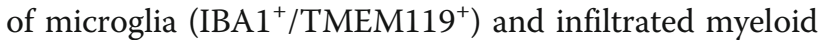




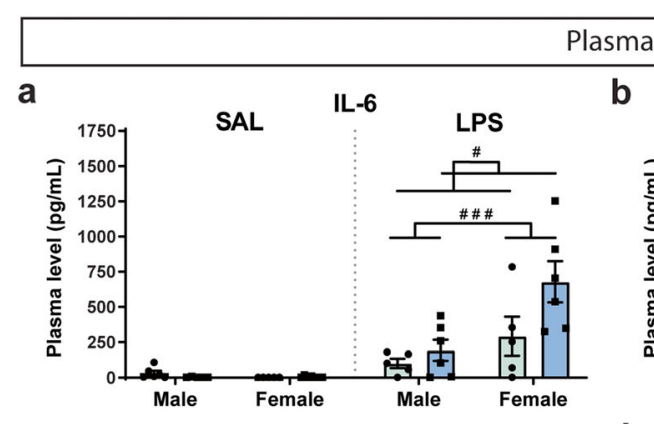

C

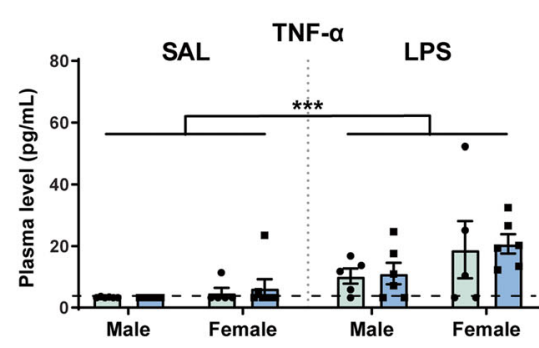

d

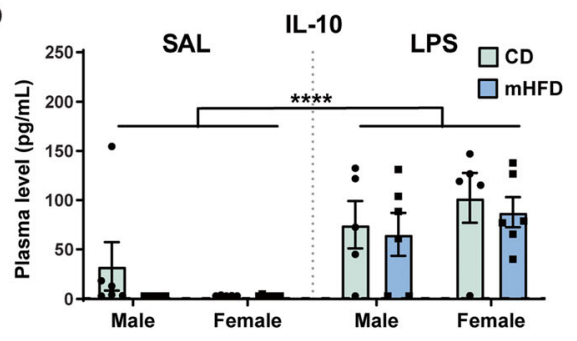

d

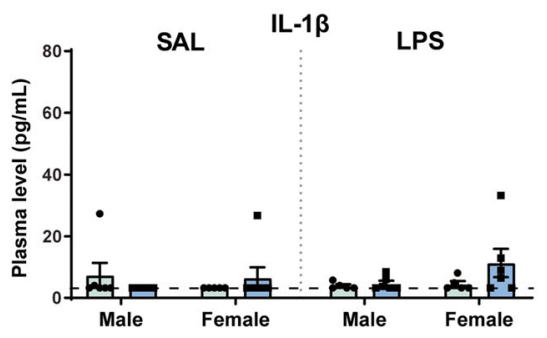

e

f
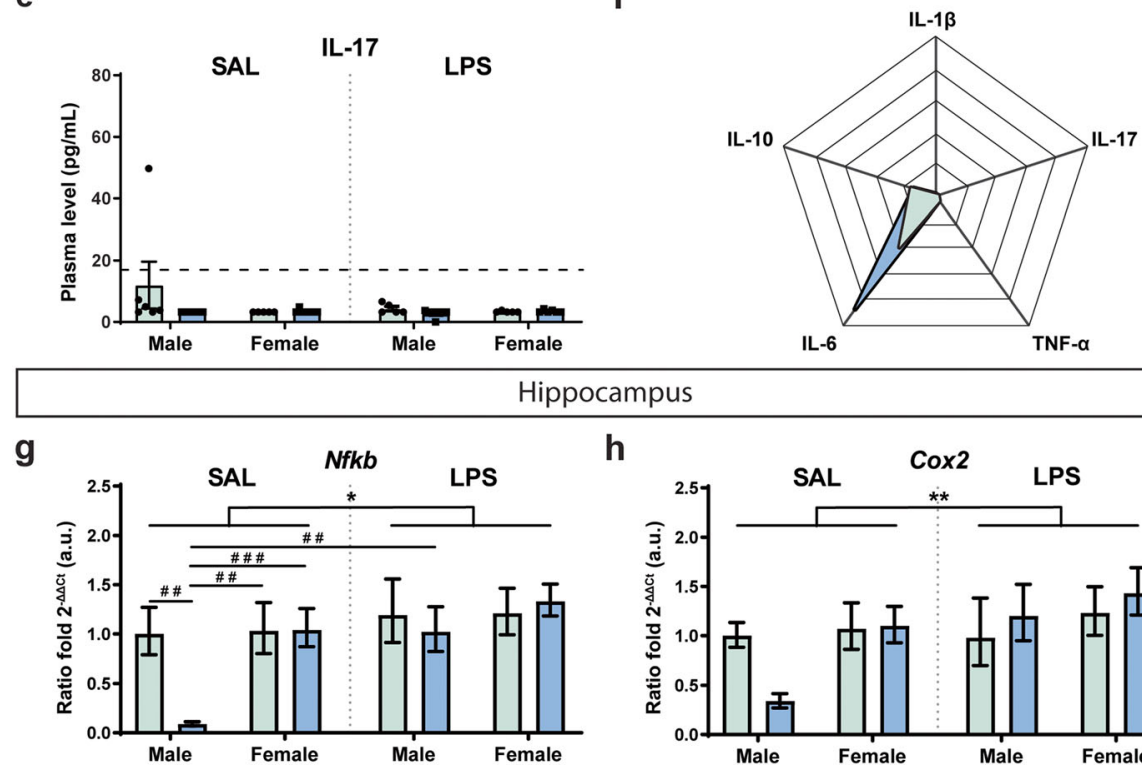

h

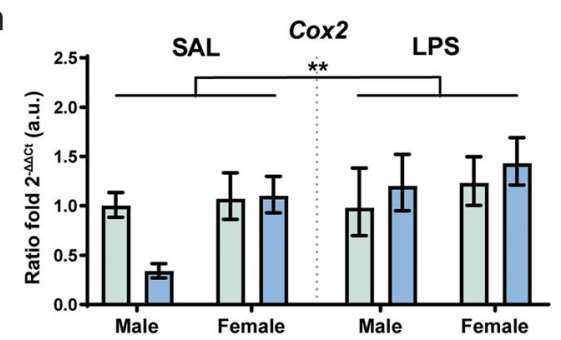

Fig. 3 mHFD effect on plasma cytokine profile and brain inflammatory profile of PND30 offspring $8 \mathrm{~h}$ after LPS treatment. a IL-1 $13, \mathbf{b} I L-17, \mathbf{c}$ TNFa, $\mathbf{d}$ IL-6, and $\mathbf{e}$ IL-10 were measured by multiplex-ELISA in offspring plasma after administration of SAL or LPS by intraperitoneal injection. Dotted line on the graphs indicates the detection limits. $\mathbf{f}$ Radar graph illustrates cytokines levels in offspring from both diet groups regardless of their sex $8 \mathrm{~h}$ after LPS immune challenge. $\mathbf{g} \mathrm{Nfkb}$ and $\mathbf{h}$ Cox $2 \mathrm{mRNA}$ levels were evaluated by rt-qPCR in offspring hippocampus after administration of SAL or LPS by intraperitoneal injection. Data are shown as mean \pm standard error of the mean. $p<0.05^{*}, p<0.001^{* * *}, p<0.0001^{* * * *}$ (treatment)

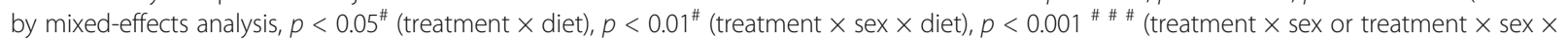
diet) by mixed-effects analysis. CD, control; Cox2, Cyclooxygenase 2; LPS, lipopolysaccharide; IL, interleukin; SAL, saline; mHFD, maternal high-fat diet; Nfkb, nuclear factor kappa B; TNF-a, tumor necrosis factor a

cells $\left(\mathrm{IBA1}^{+} / \mathrm{TMEM}^{-} 19^{-}\right)$were similar between groups (Table 3; Fig. 5j, w). Of note, infiltrated myeloid cells were marginal, accounting for $0.207 \%$ of IBA1+ cells in the $s t$ rad and $0.240 \%$ in st lac mol. Regardless of their sex and maternal diet, adolescent offspring displayed similar values for microglial soma, arbor, and cell area, as well as morphological index (soma area/manual arborization area) in both CA1 st rad and st lac mol (Tables 4 and 5; Fig. 5f-i, $\mathrm{s}-\mathrm{v})$. In st rad, further analysis of "skeletonized" microglia revealed no significant difference between offspring groups in terms of number of branches, junctions, as well as average and maximal branch length (Table 4; Fig. $5 \mathrm{~m}$ ). However, shape descriptor analysis of microglia identified a significant decrease in their circularity value $\left(F_{(1,16)}=\right.$ 
Table 2 mHFD effect on hippocampal mRNA levels of PND30 offspring

\begin{tabular}{|c|c|c|c|c|c|c|c|}
\hline \multirow[t]{2}{*}{ Gene } & \multirow[t]{2}{*}{ Treatment } & \multicolumn{2}{|l|}{ Male } & \multicolumn{2}{|l|}{ Female } & \multirow[t]{2}{*}{$F$} & \multirow[t]{2}{*}{$p$} \\
\hline & & $C D$ & mHFD & $C D$ & mHFD & & \\
\hline \multirow[t]{2}{*}{$N f \kappa b$} & SAL & $\begin{array}{l}2^{-\Delta \Delta C t}=1.000 \\
\Delta \Delta C t=0.000 \\
\pm 0.344\end{array}$ & $\begin{array}{l}2^{-\Delta \Delta C t}=0.090 \\
\Delta \Delta C t=2.633 \pm \\
0.833\end{array}$ & $\begin{array}{l}2^{-\Delta \Delta C t}=1.030 \\
\Delta \Delta C t=0.038 \pm \\
0.360\end{array}$ & $\begin{array}{l}2^{-\Delta \Delta C t}=1.040 \\
\Delta \Delta C t=0.630 \pm \\
0.569\end{array}$ & \multirow{2}{*}{$\begin{array}{l}\text { Treatment } \times \text { sex } \times \\
\text { diet, } 5.344 \\
\text { Treatment } \times \text { sex, } \\
5.513 \\
\text { Treatment } \times \text { diet, } \\
2.523 \\
\text { Sex } \times \text { diet, } 8.428 \\
\text { Treatment, } 5.646 \\
\text { Sex, } 8.928 \\
\text { Diet, } 2.926\end{array}$} & \multirow{2}{*}{$\begin{array}{l}\text { Treatment } \times \text { sex } \times \text { diet, } \\
\mathbf{0 . 0 2 6 5 ^ { * }} \\
\text { Treatment } \times \text { sex, } \\
\mathbf{0 . 0 2 4 3}^{*} \\
\text { Treatment } \times \text { diet, } 0.1207 \\
\text { Sex } \times \text { diet, } \mathbf{0 . 0 0 6 2 ^ { * * }} \\
\text { Treatment, } \mathbf{0 . 0 2 2}^{*} \\
\text { Sex, } \mathbf{0 . 0 0 5 0 ^ { * * }} \\
\text { Diet, } 0.0955\end{array}$} \\
\hline & LPS & $\begin{array}{l}2^{-\Delta \Delta C t}=1.190 \\
\Delta \Delta C t=0.255 \pm \\
0.385\end{array}$ & $\begin{array}{l}2^{-\Delta \Delta C t}=1.020 \\
\Delta \Delta C t=0.034 \pm \\
0.317\end{array}$ & $\begin{array}{l}2^{-\Delta \Delta C t}=1.210 \\
\Delta \Delta C t=0.270 \pm \\
0.281\end{array}$ & $\begin{array}{l}2^{-\Delta \Delta C t}=1.330 \\
\Delta \Delta C t=0.415 \pm \\
0.175\end{array}$ & & \\
\hline \multirow[t]{2}{*}{$\operatorname{Cox} 2$} & SAL & $\begin{array}{l}2^{-\Delta \Delta C t}=1.000 \\
\Delta \Delta C t=0.000 \pm \\
0.182\end{array}$ & $\begin{array}{l}2^{-\Delta \Delta C t}=0.340 \\
\Delta \Delta C t=1.574 \pm \\
0.312\end{array}$ & $\begin{array}{l}2^{-\Delta \Delta C t}=1.070 \\
\Delta \Delta C t=0.101 \pm \\
0.324\end{array}$ & $\begin{array}{l}2^{-\Delta \Delta C t}=1.100 \\
\Delta \Delta C t=0.133 \pm \\
0.242\end{array}$ & \multirow{2}{*}{$\begin{array}{l}\text { Treatment } \times \text { sex } \times \\
\text { diet, } 3.711 \\
\text { Treatment } \times \text { sex, } \\
2.052 \\
\text { Treatment } \times \text { diet, } \\
5.596 \\
\text { Sex } \times \text { diet, } 3.170 \\
\text { Treatment, } 7.608 \\
\text { Sex, } 7.507 \\
\text { Diet, } 1.419\end{array}$} & \multirow{2}{*}{$\begin{array}{l}\text { Treatment } \times \text { sex } \times \text { diet, } \\
0.0618 \\
\text { Treatment } \times \text { sex, } 0.1604 \\
\text { Treatment } \times \text { diet, } \\
\mathbf{0 . 0 2 3 3}^{*} \\
\text { Sex } \times \text { diet, } 0.0832 \\
\text { Treatment, } \mathbf{0 . 0 0 9 0 ^ { * * }} \\
\text { Sex, } \mathbf{0 . 0 0 9 4 ^ { * * }} \\
\text { Diet, } 0.2412\end{array}$} \\
\hline & LPS & $\begin{array}{l}2^{-\Delta \Delta C t}=0.980 \\
\Delta \Delta C t=0.022 \pm \\
0.490\end{array}$ & $\begin{array}{l}2^{-\Delta \Delta C t}=1.200 \\
\Delta \Delta C t=0.264 \pm \\
0.342\end{array}$ & $\begin{array}{l}2^{-\Delta \Delta C t}=1.230 \\
\Delta \Delta C t=0.293 \pm \\
0.289\end{array}$ & $\begin{array}{l}2^{-\Delta \Delta C t}=1.430 \\
\Delta \Delta C t=0.516 \pm \\
0.242\end{array}$ & & \\
\hline$T g f b 1$ & - & $\begin{array}{l}2^{-\Delta \Delta C t}=1.000 \\
\Delta \Delta C t=0.000 \pm \\
0.218\end{array}$ & $\begin{array}{l}2^{-\Delta \Delta C t}=0.2764 \\
\Delta \Delta C t=1.860 \pm \\
0.262\end{array}$ & $\begin{array}{l}2^{-\Delta \Delta C t}=1.139 \\
\Delta \Delta C t=-0.190 \pm \\
0.407\end{array}$ & $\begin{array}{l}2^{-\Delta \Delta C t}=1.282 \\
\Delta \Delta C t=-0.360 \pm \\
0.335\end{array}$ & $\begin{array}{l}\text { Sex } \times \text { diet, } 10.05 \\
\text { Sex, } 14.16 \\
\text { Diet, } 6.965\end{array}$ & 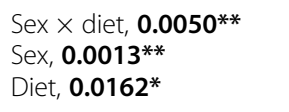 \\
\hline Aif1 & - & $\begin{array}{l}2^{-\Delta \Delta C t}=1.000 \\
\Delta \Delta C t=0.000 \pm \\
0.328\end{array}$ & $\begin{array}{l}2^{-\Delta \Delta C t}=0.7169 \\
\Delta \Delta C t=0.480 \pm \\
0.340\end{array}$ & $\begin{array}{l}2^{-\Delta \Delta C t}=1.069 \\
\Delta \Delta C t=-0.100 \pm \\
0.290\end{array}$ & $\begin{array}{l}2^{-\Delta \Delta C t}=1.196 \\
\Delta \Delta C t=-0.260 \pm \\
0.299\end{array}$ & $\begin{array}{l}\text { Sex } \times \text { diet, } 1.035 \\
\text { Sex, } 1.783 \\
\text { Diet, } 0.2588\end{array}$ & $\begin{array}{l}\text { Sex } \times \text { diet, } 0.3218 \\
\text { Sex, } 0.1976 \\
\text { Diet, } 0.6168\end{array}$ \\
\hline Tmem119 & - & $\begin{array}{l}2^{-\Delta \Delta C t}=1.000 \\
\Delta \Delta C t=0.000 \pm \\
0.313\end{array}$ & $\begin{array}{l}2^{-\Delta \Delta C t}=0.1346 \\
\Delta \Delta C t=2.89 \pm \\
0.269\end{array}$ & $\begin{array}{l}2^{-\Delta \Delta C t}=1.260 \\
\Delta \Delta C t=-0.330 \pm \\
0.350\end{array}$ & $\begin{array}{l}2^{-\Delta \Delta C t}=1.101 \\
\Delta \Delta C t=-0.140 \pm \\
0.265\end{array}$ & $\begin{array}{l}\text { Sex } \times \text { diet, } 19.47 \\
\text { Sex, } 30.15 \\
\text { Diet, } 25.34\end{array}$ & $\begin{array}{l}\text { Sex } \times \text { diet, } 0.0003^{* * *} \\
\text { Sex },<0.0001^{* * * * *} \\
\text { Diet, }<0.0001^{* * * *}\end{array}$ \\
\hline Trem2 & - & $\begin{array}{l}2^{-\Delta \Delta C t}=1.000 \\
\Delta \Delta C t=0.000 \pm \\
0.282\end{array}$ & $\begin{array}{l}2^{-\Delta \Delta C t}=0.1690 \\
\Delta \Delta C t=2.570 \pm \\
0.229\end{array}$ & $\begin{array}{l}2^{-\Delta \Delta C t}=0.9781 \\
\Delta \Delta C t=0.030 \pm \\
0.326\end{array}$ & $\begin{array}{l}2^{-\Delta \Delta C t}=0.9598 \\
\Delta \Delta C t=0.060 \pm \\
0.242\end{array}$ & $\begin{array}{l}\text { Sex } \times \text { diet, } 20.88 \\
\text { Sex, } 19.90 \\
\text { Diet, } 21.88\end{array}$ & 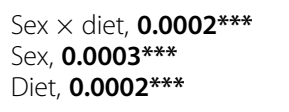 \\
\hline$C \times 3 c r 1$ & - & $\begin{array}{l}2^{-\Delta \Delta C t}=1.000 \\
\Delta \Delta C t=0.000 \pm \\
0.203\end{array}$ & $\begin{array}{l}2^{-\Delta \Delta C t}=0.1724 \\
\Delta \Delta C t=2.520 \pm \\
0.479\end{array}$ & $\begin{array}{l}2^{-\Delta \Delta C t}=1.147 \\
\Delta \Delta C t=-0.200 \pm \\
0.315\end{array}$ & $\begin{array}{l}2^{-\Delta \Delta C t}=1.207 \\
\Delta \Delta C t=-0.270 \pm \\
0.276\end{array}$ & $\begin{array}{l}\text { Sex } \times \text { diet, } 16.44 \\
\text { Sex, } 21.92 \\
\text { Diet, } 14.71\end{array}$ & 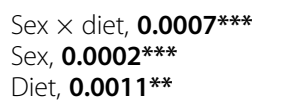 \\
\hline
\end{tabular}

Transcripts level of Nfkb, Cox2, Tgf1b, Aif1, Tmem119, Trem2, and Cx3cr1 were normalized by Rp/32, where SAL-CD male or CD male offspring represent the reference group. Nfkb and Cox2 were measured $8 \mathrm{~h}$ after LPS-induced immune challenge, while Tgf1b, Aif1, Tmem119, Trem2, and CX3cr1 were evaluated in homeostatic condition.

$2^{-\Delta \Delta C t}$ ratio fold compared to expression of the reference group, $\Delta \Delta \mathrm{Ct}$ difference of cycle threshold between $\Delta \mathrm{Ct}$ of the target gene and $\Delta \mathrm{Ct}$ of Rpl32, Aif1 allograft inflammatory factor 1, CD control diet, Cox2 cyclooxygenase 2, Cx3cr1 fractalkine receptor, LPS lipopolysaccharide, mHFD maternal high-fat diet, Nfkb nuclear factor kappa B, SAL saline, Tgfb1 transforming growth factor $\beta 1$, Tmem 119 transmembrane protein 119, Trem2 triggering receptor expressed by myeloid cells $2, P$-values of significant statistical tests are in bold and followed by the number of asterisks indicating their significativity, $p<0.05^{*}, p<0.01^{* *}, p<0.001^{* * *}$, $p<0.0001^{* * * *}$

4.683, $p=0.0459)$ in mHFD offspring compared to controls $(0.0265 \pm 0.0004$ vs $0.0295 \pm 0.0006)$, but solidity and aspect ratio remained unchanged (Table 4; Fig. $5 \mathrm{k}-\mathrm{l}$ ). In $s t$ lac mol, microglia of mHFD-exposed offspring had significantly shorter branch length $\left(F_{(1,16)}=4.553, p=0.0487\right)$ compared to CD-exposed offspring $(3.276 \pm 0.015 \mu \mathrm{m}$ vs $3.442 \pm 0.022 \mu \mathrm{m}$ ) (Table 5; Fig. 5z). In addition to their shorter branch length, microglia of mHFD-exposed offspring had a significantly increased solidity $\left(F_{(1,16)}=5.616\right.$, $p=0.0307)$ compared to CD offspring $(0.2845 \pm 0.0030$ vs $0.2603 \pm 0.0023$ ), regardless of the sex (Table 5; Fig. 5y), which could indicate a difference in microglial arborization distribution and/or organization with mHFD. In this layer, microglial branch number, maximal branch length, junction number, circularity, and aspect ratio were also similar between groups. Together, these morphological changes align with a microglial priming hypothesis, in which mHFD alters microglial morphology.

\section{Microglia from mHFD male offspring show increased interactions with astrocytes whereas both male and female offspring have decreased extracellular space pockets}

To provide insights into microglial functions, we further performed SEM analysis to reveal, at nanoscale resolution, possible changes in their organelles and intercellular relationships in the dorsal hippocampus CA1 of mHFD- vs CD-exposed offspring, upon sacrifice at PND30. We determined the number of microglial organelles involved in phagolysosomal activity (primary, 


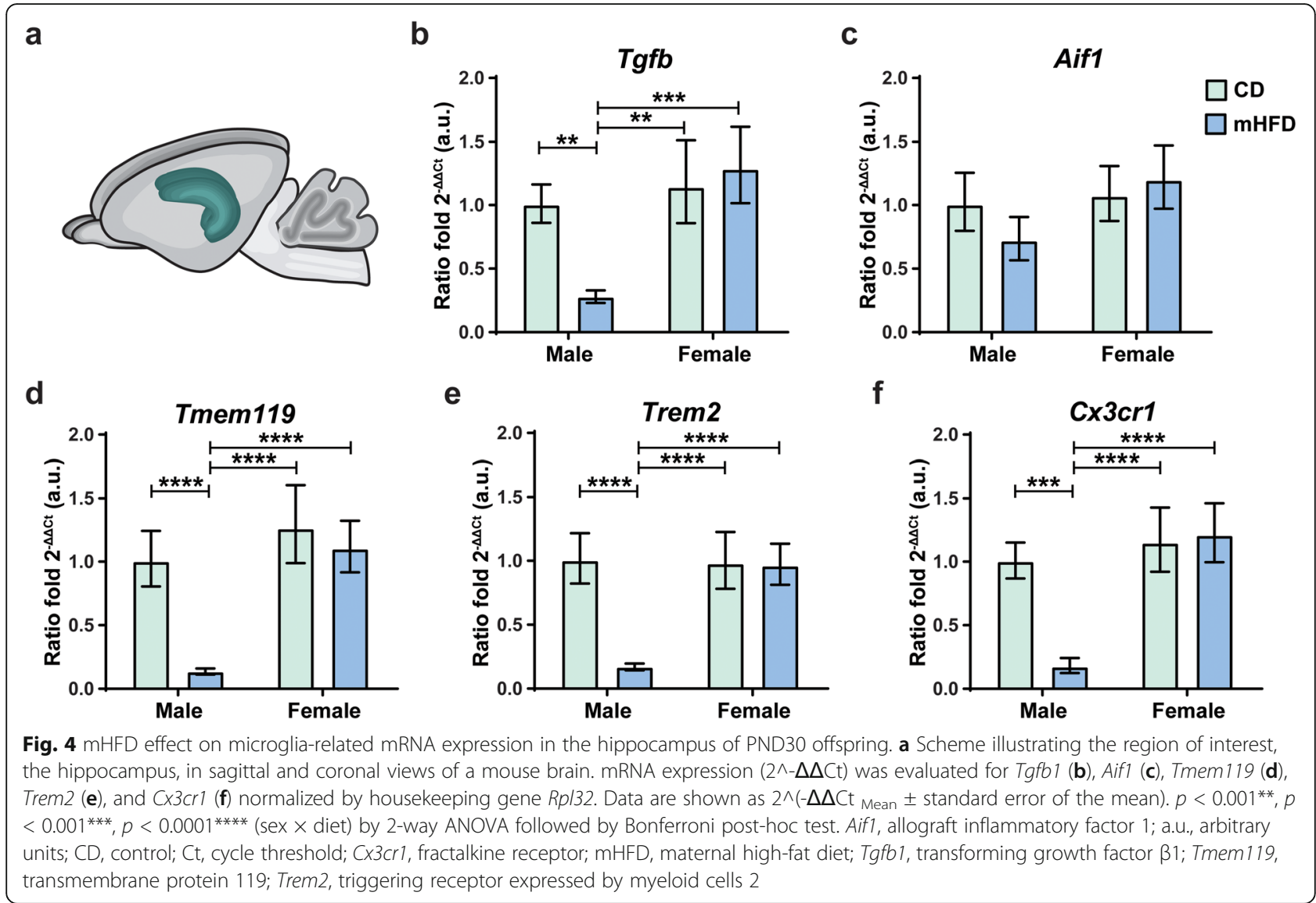

secondary and tertiary lysosomes, lipofuscin, endosomes with or without content) and alterations to organelles that serve as markers of cellular stress (dilated cisternae of endoplasmic reticulum and Golgi apparatus, elongated and total mitochondria). We also evaluated microglial interactions with their microenvironment, particularly direct contacts with astrocytic cell bodies, neuronal cell bodies, axon terminals, dendritic spines, oligodendrocytic cell bodies, myelinated axons, and blood vessels, as well as associations with extracellular space pockets containing degraded elements or debris indicative of extracellular digestion or "exophagy" $[67,68]$.

In the st rad, no significant difference in microglial organelles was observed between offspring groups, but there was a trend for a main diet effect regarding the total number of mitochondria per microglial cell body $\left(F_{(1,146)}=3.870, p=\right.$ 0.0511 ) (Table 6). In terms of microglial interactions with their microenvironment, we detected a sex $\times$ diet interaction for the number of microglial contacts with astrocytes $\left(F_{(1,146)}=0.0446\right)$. Post-hoc analysis revealed that microglial cell bodies from mHFD-exposed male offspring made more cell-cell contacts with astrocytic cell bodies compared to CD male offspring ( $p=0.0182,0.225 \pm 0.067$ contacts vs $0.054 \pm 0.038$ contacts) (Table 6; Fig. 6a-e). Microglial interactions with synaptic elements, myelinated axons, neurons as well as oligodendrocytes remained unchanged (Table 6). We also identified a sex $\times$ diet interaction for the prevalence of microglia-associated extracellular digestion $\left(F_{(1,146)}=0.0433\right)$; however, post-hoc analysis revealed no significant different between offspring groups (Table 6).

In st lac mol, microglial organelle content and ultrastructure were unaffected by offspring groups (Table 7), but their interactions with the microenvironment differed. Similar to microglia in the st rad, microglial cell bodies in st lac mol of mHFD-exposed male offspring had increased interactions with astrocytic cell bodies $\left(F_{(1,128)}=4.604, p=\right.$ $0.0446)$ compared to CD male offspring $(0.028 \pm 0.028$ contacts vs $0.214 \pm 0.094$ contacts) (Table 7; Fig. 6a-e, h-k, q). Of note, a significant main sex effect was also detected for microglial interactions with neurons $\left(F_{(1,128)}=6.062, p=\right.$ 0.0151 ), where microglial cell bodies from male offspring compared to female offspring made more cell-cell contacts with neuronal cell bodies, regardless of maternal diet $(0.081$ \pm 0.026 contacts vs $0.000 \pm 0.000$ contacts) (Table 7; Fig. $6 \mathrm{~h}-\mathrm{k}, \mathrm{r})$. Microglial interactions with synaptic elements, oligodendrocytes, and myelinated axons were also unchanged across sex and diet groups (Table 7). Lastly, mHFDexposed offspring had a significant decrease $\left(F_{(1,128)}=\right.$ 7.666, $p=0.0065)$ in microglia-associated extracellular space pockets compared to CD offspring (0.1374 \pm 0.0768 

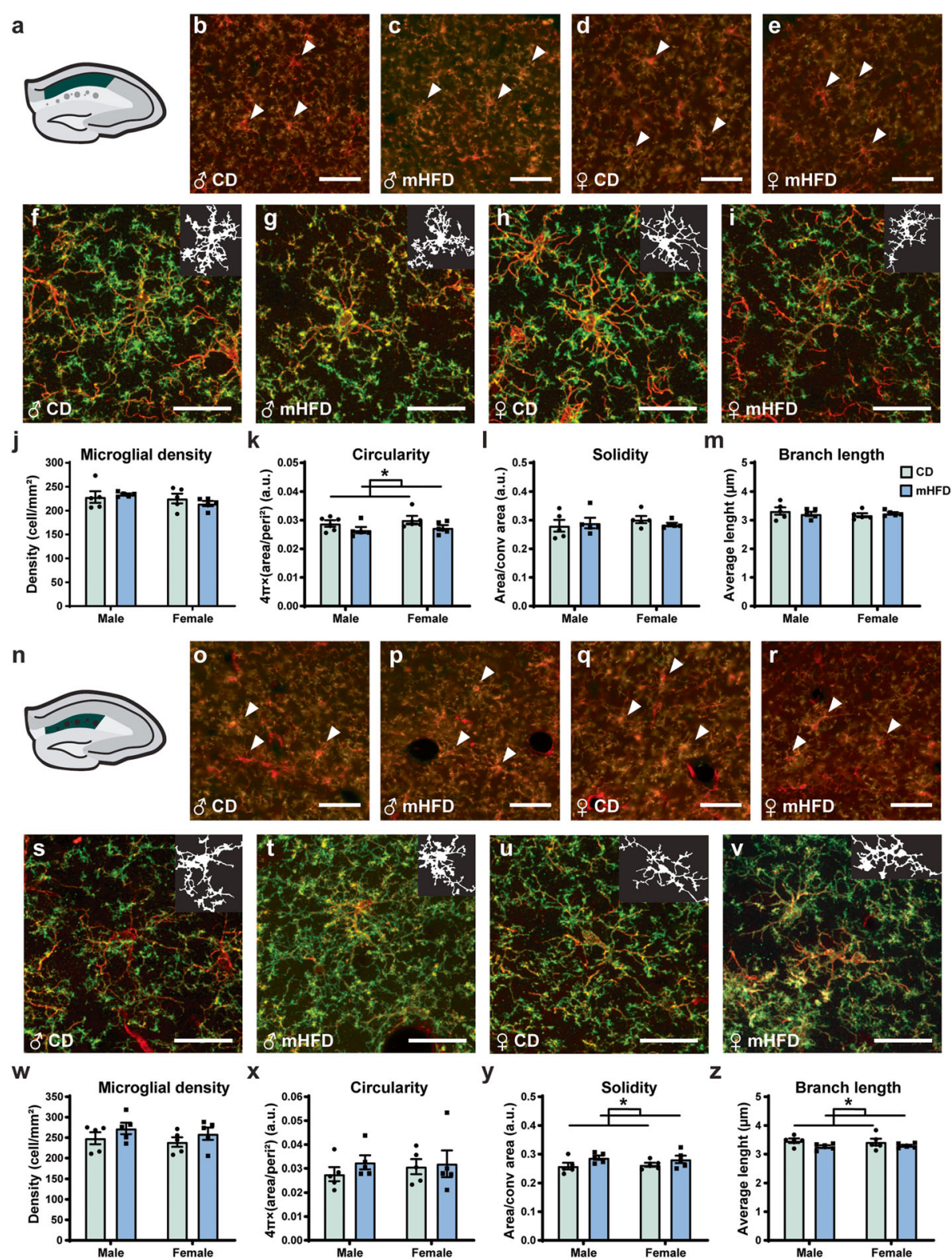

Fig. 5 mHFD effect on microglial density, distribution, and morphology in the dorsal hippocampus CA1 of PND30 offspring. Representative scheme of the a st rad and $\mathbf{n}$ st lac mol to illustrate the layers analyzed. Immunofluorescence (IBA1+ low). Immunofluorescence IBA1 (red) and TMEM119 (green) allowed analysis of (b-e, o-r) microglial number and morphology ( $\mathbf{f}-\mathbf{i}, \mathbf{s}-\mathbf{v})$. Scale bar for the density pictures is equivalent to $50 \mu \mathrm{m}(\mathbf{b}-\mathbf{e}, \mathbf{o}-\mathbf{r})$, whereas scale bar for morphology pictures is $25 \mu \mathrm{m}(\mathbf{f}-\mathbf{i}, \mathbf{s}-\mathbf{v})$. For each morphology picture, mask of the cell (IBA ${ }^{+}$staining) is represented in the upper right corner. Only $(\mathbf{j}, \mathbf{w})$ microglial density and main differences in morphology ( $\mathbf{k}, \mathbf{x}$ circularity; $\mathbf{l}, \mathbf{y}$ solidity; and $\mathbf{m}, \mathbf{z}$ branch length average) are presented on the figure. Data are shown as mean \pm standard error of the mean. $p<0.05^{*}$ (diet) by 2-way ANOVA., , female; $\widehat{O}$, male; CD, control; Conv area, convex area; mHFD, maternal high-fat diet; Peri, perimeter

contacts vs $0.5349 \pm 0.0206$ contacts) (Table 7; Fig. 6l-o, s) in the two sexes.

Dark microglia and perivascular cells display increased number of dilated endoplasmic reticulum and Golgi apparatus cisterna in mHFD offspring

Previously, our laboratory identified a microglial subset, the "dark microglia," which is characterized by a distinct ultrastructural signature compared with typical microglia. These cells are found within the brain parenchyma, notably in the ventral/dorsal hippocampus CA1 st rad and st lac mol. Dark microglia exhibit several markers of cellular stress (dilatation of endoplasmic reticulum and Golgi, elongated mitochondria) as well as a dark, electron-dense cytoplasm, and nucleoplasm [69]. These stressed microglia are rare in healthy mature mice but become abundant in 
Table 3 mHFD effects on microglial density, distribution, and peripheral myeloid cell infiltration in the dorsal hippocampus CA1 of PND30 offspring

\begin{tabular}{|c|c|c|c|c|c|c|c|}
\hline \multirow[t]{3}{*}{ Parameters } & & \multicolumn{4}{|c|}{ Mean \pm standard error of the mean } & \multirow[t]{3}{*}{$F$} & \multirow[t]{3}{*}{$p$} \\
\hline & & \multicolumn{2}{|l|}{ Male } & \multicolumn{2}{|l|}{ Female } & & \\
\hline & & $\overline{C D}$ & mHFD & $\overline{C D}$ & $\mathrm{mHFD}$ & & \\
\hline \multirow[t]{4}{*}{ Strad } & Density (cells/mm²) & $228.5 \pm 12.1$ & $233.8 \pm 2.1$ & $225.4 \pm 10.1$ & $214.9 \pm 5.4$ & $\begin{array}{l}\text { Sex } \times \text { diet, } 0.8838 \\
\text { Sex, } 1.725 \\
\text { Diet, } 0.09162\end{array}$ & $\begin{array}{l}\text { Sex } \times \text { diet, } 0.3611 \\
\text { Sex, } 0.2075 \\
\text { Diet, } 0.7660\end{array}$ \\
\hline & Spacing Index (a.u.) & $0.452 \pm 0.014$ & $0.469 \pm 0.006$ & $0.456 \pm 0.011$ & $0.454 \pm 0.013$ & $\begin{array}{l}\text { Sex } \times \text { diet, } 0.6857 \\
\text { Sex, } 0.2303 \\
\text { Diet, } 0.4325\end{array}$ & $\begin{array}{l}\text { Sex } \times \text { diet, } 0.4198 \\
\text { Sex, } 0.6378 \\
\text { Diet, } 0.5201\end{array}$ \\
\hline & Cluster & $0.261 \pm 0.138$ & $0.051 \pm 0.031$ & $0.182 \pm 0.084$ & $0.222 \pm 0.091$ & $\begin{array}{l}\text { Sex } \times \text { diet, } 1.759 \\
\text { Sex, } 0.2359 \\
\text { Diet, } 0.8177\end{array}$ & $\begin{array}{l}\text { Sex } \times \text { diet, } 0.2034 \\
\text { Sex, } 0.6338 \\
\text { Diet, } 0.3793\end{array}$ \\
\hline & \%Infiltration & $0.201 \pm 0.131$ & $0.150 \pm 0.092$ & $0.270 \pm 0.143$ & $0.000 \pm 0.000$ & $\begin{array}{l}\text { Sex } \times \text { diet, } 1.031 \\
\text { Sex, } 0.1433 \\
\text { Diet, } 2.241\end{array}$ & $\begin{array}{l}\text { Sex } \times \text { diet, } 0.3250 \\
\text { Sex, } 0.7100 \\
\text { Diet, 0.1539 }\end{array}$ \\
\hline \multirow[t]{4}{*}{ St lac mol } & Density (cells/mm²) & $248.8 \pm 14.5$ & $272.7 \pm 14.2$ & $239.4 \pm 11.8$ & $259.6 \pm 15.0$ & $\begin{array}{l}\text { Sex } \times \text { diet, } 0.01730 \\
\text { Sex, } 0.6481 \\
\text { Diet, } 2.507\end{array}$ & $\begin{array}{l}\text { Sex } \times \text { diet, } 0.8970 \\
\text { Sex, } 0.4326 \\
\text { Diet, } 0.1329\end{array}$ \\
\hline & Spacing Index (a.u.) & $0.473 \pm 0.019$ & $0.466 \pm 0.004$ & $0.442 \pm 0.016$ & $0.470 \pm 0.022$ & $\begin{array}{l}\text { Sex } \times \text { diet, } 1.105 \\
\text { Sex, } 0.6448 \\
\text { Diet, } 0.4185\end{array}$ & $\begin{array}{l}\text { Sex } \times \text { diet, } 0.3089 \\
\text { Sex, } 0.4337 \\
\text { Diet, } 0.5268\end{array}$ \\
\hline & Cluster & $0.122 \pm 0.062$ & $0.179 \pm 0.093$ & $0.029 \pm 0.029$ & $0.147 \pm 0.065$ & $\begin{array}{l}\text { Sex } \times \text { diet, } 0.2179 \\
\text { Sex, } 0.9011 \\
\text { Diet, } 1.739\end{array}$ & $\begin{array}{l}\text { Sex } \times \text { diet, } 0.6469 \\
\text { Sex, } 0.3566 \\
\text { Diet, } 0.2058\end{array}$ \\
\hline & \%Infiltration & $0.073 \pm 0.073$ & $0.437 \pm 0.151$ & $0.233 \pm 0.154$ & $0.216 \pm 0.091$ & $\begin{array}{l}\text { Sex } \times \text { diet, } 2.421 \\
\text { Sex, } 0.06043 \\
\text { Diet, } 2.006\end{array}$ & $\begin{array}{l}\text { Sex } \times \text { diet, } 0.1393 \\
\text { Sex, } 0.8089 \\
\text { Diet, } 0.1758\end{array}$ \\
\hline
\end{tabular}

\%Infiltration average percentage of IBA $1^{+} / \mathrm{TMEM} 119^{-}$cells on total myeloid cells count, a.u. arbitrary unit, $C D$ control diet, $\mathrm{mHFD}$ maternal high-fat diet, St lac mol stratum lacunosum moleculare, St rad stratum radiatum

pathological conditions [69] including in a MIA mouse model induced with polyinosinic polycytidylic acid (polyinosinic-polycytidylic acid) [54]. In the current study, we characterized the density and ultrastructure of dark microglia in the dorsal hippocampus CA1, st rad and st lac mol, comparing mHFD with CD offspring at PND30. While imaging, we also noticed intriguing dark perivascular cells, localized inside the perivascular space yet displaying dark features similar to the dark microglia (i.e., dark, electron-dense cytoplasm, and nucleoplasm, as well as markers of cellular stress). We further encountered apoptotic cells, identified by their dark cytoplasm, which was accompanied in this case by a distinctive pyknotic and fragmented nucleus. We decided to also quantify their density. The quantitative analysis of dark microglia and apoptotic cells revealed no significant difference in their density among the st rad and st lac mol of the adolescent offspring, regardless of their sex and maternal diet (Supplementary Table 1; Fig. $7 \mathrm{a}-\mathrm{c}$ ). Notwithstanding, more than half of the apoptotic cells we observed (four out of seven) were identified as microglia by their $\mathrm{IBA} 1^{+}$staining. In the st rad, dark perivascular cells also displayed a similar density between offspring groups. In the st lac mol, however, a sex difference was observed, with the female offspring showing a significantly increased density of dark perivascular cells $\left(F_{(1,12)}=5.692, p=0.0344\right)$ compared to male offspring $\left(12.58 \pm 1.99 \mathrm{cell} / \mathrm{mm}^{2}\right.$ vs $0.94 \pm 0.94 \mathrm{cell} /$ $\mathrm{mm}^{2}$ ) (Supplementary Table 1; Fig. $7 \mathrm{~d}-\mathrm{e}$ ); regardless of maternal diet.

To study changes in organelles among the stressed dark cells in the st lac mol, we pooled together dark microglia and dark perivascular cells to obtain a sufficient sample size, required to be around 50 individual cells total for a large effect size ( $\sim 0.4)$ (also see Supplementary Table 2 for the semi-descriptive analysis of the dark microglia and dark perivascular cells considered separately). This quantitative analysis of dark cells revealed a main diet effect on their number of dilated endoplasmic reticulum or Golgi apparatus cisternae, which significantly increased $\left(F_{(1,55)}=4.264, p=0.0437\right)$ in mHFD compared to CD offspring (14.38 $\pm 0.62 \mathrm{di}-$ lated cisterna vs $9.805 \pm 3.090$ dilated cisterna) (Supplementary Table 3; Fig. 7f-j). In addition, secondary lysosomes were significantly more abundant in female offspring compared to male offspring regardless of their maternal diet (female offspring $0.453 \pm 0.120$ lysosomes vs male offspring $0.077 \pm 0.109$ lysosomes) (Supplementary Table 3). This finding may describe a sex difference, regardless of maternal diet, in terms of dark cells phagolysosomal pathways. Across groups, the two types of 
Table 4 mHFD effects on microglial morphological parameters in the dorsal hippocampus CA1 stratum radiatum of PND30 offspring

\begin{tabular}{|c|c|c|c|c|c|c|}
\hline \multirow[t]{3}{*}{ Parameters } & \multicolumn{4}{|c|}{ Mean \pm standard error of the mean } & \multirow[t]{3}{*}{$F$} & \multirow[t]{3}{*}{$p$} \\
\hline & \multicolumn{2}{|l|}{ Male } & \multicolumn{2}{|l|}{ Female } & & \\
\hline & $C D$ & mHFD & $C D$ & mHFD & & \\
\hline Soma area $\left(\mu m^{2}\right)$ & $46.59 \pm 1.92$ & $46.88 \pm 2.54$ & $44.42 \pm 1.38$ & $45.82 \pm 1.84$ & $\begin{array}{l}\text { Sex } \times \text { diet, } 0.08109 \\
\text { Sex, } 0.6758 \\
\text { Diet, } 0.1842\end{array}$ & $\begin{array}{l}\text { Sex } \times \text { diet, } 0.7795 \\
\text { Sex, } 0.4231 \\
\text { Diet, } 0.6735\end{array}$ \\
\hline Arbor area $\left(\mu m^{2}\right)$ & $\begin{array}{l}1352.68 \pm \\
154.93\end{array}$ & $\begin{array}{l}1355.63 \pm \\
112.22\end{array}$ & $\begin{array}{l}1374.23 \pm \\
160.96\end{array}$ & $\begin{array}{l}1377.16 \pm \\
129.59\end{array}$ & $\begin{array}{l}\text { Sex } \times \text { diet, } 4.378 \times \\
10^{-9} \\
\text { Sex, } 0.02340 \\
\text { Diet, } 0.0004357\end{array}$ & $\begin{array}{l}\text { Sex } \times \text { diet, }> \\
0.9999 \\
\text { Sex, } 0.8803 \\
\text { Diet, } 0.9836\end{array}$ \\
\hline Morphological index (a.u.) & $0.036 \pm 0.003$ & $0.035 \pm 0.001$ & $0.034 \pm 0.003$ & $0.035 \pm 0.004$ & $\begin{array}{l}\text { Sex } \times \text { diet, } 0.09893 \\
\text { Sex, } 0.1851 \\
\text { Diet, } 0.0001109\end{array}$ & $\begin{array}{l}\text { Sex } \times \text { diet, } 0.7572 \\
\text { Sex, } 0.6728 \\
\text { Diet, } 0.9917\end{array}$ \\
\hline Cell area $\left(\mu m^{2}\right)$ & $425.49 \pm 86.24$ & $430.71 \pm 55.12$ & $473.40 \pm 79.36$ & $435.13 \pm 49.86$ & $\begin{array}{l}\text { Sex } \times \text { diet, } 0.09819 \\
\text { Sex, } 0.1422 \\
\text { Diet, } 0.05674\end{array}$ & $\begin{array}{l}\text { Sex } \times \text { diet, } 0.7581 \\
\text { Sex, } 0.7110 \\
\text { Diet, } 0.8148\end{array}$ \\
\hline Circularity (a.u.) & $0.029 \pm 0.001$ & $0.027 \pm 0.001$ & $0.030 \pm 0.001$ & $0.027 \pm 0.001$ & $\begin{array}{l}\text { Sex } \times \text { diet, } 0.03614 \\
\text { Sex, } 0.7875 \\
\text { Diet, } 4.683\end{array}$ & $\begin{array}{l}\text { Sex } \times \text { diet, } 0.8516 \\
\text { Sex, } 0.3880 \\
\text { Diet, 0.0459* }\end{array}$ \\
\hline Solidity (a.u.) & $0.281 \pm 0.020$ & $0.290 \pm 0.018$ & $0.302 \pm 0.012$ & $0.285 \pm 0.006$ & $\begin{array}{l}\text { Sex } \times \text { diet, } 0.7345 \\
\text { Sex, } 0.2907 \\
\text { Diet, } 0.07122\end{array}$ & $\begin{array}{l}\text { Sex } \times \text { diet, } 0.4041 \\
\text { Sex, } 0.5972 \\
\text { Diet, } 0.7930\end{array}$ \\
\hline Aspect ratio (a.u.) & $1.666 \pm 0.055$ & $1.648 \pm 0.053$ & $1.633 \pm 0.065$ & $1.663 \pm 0.069$ & $\begin{array}{l}\text { Sex } \times \text { diet, } 0.1587 \\
\text { Sex, } 0.02512 \\
\text { Diet, } 0.008885\end{array}$ & $\begin{array}{l}\text { Sex } \times \text { diet, } 0.6956 \\
\text { Sex, } 0.8761 \\
\text { Diet, } 0.9261\end{array}$ \\
\hline \# Branches & $101.92 \pm 21.70$ & $104.47 \pm 13.79$ & $113.11 \pm 17.14$ & $102.23 \pm 12.52$ & $\begin{array}{l}\text { Sex } \times \text { diet, } 0.1622 \\
\text { Sex, } 0.07200 \\
\text { Diet, } 0.06261\end{array}$ & $\begin{array}{l}\text { Sex } \times \text { diet, } 0.6925 \\
\text { Sex, } 0.7919 \\
\text { Diet, } 0.8056\end{array}$ \\
\hline $\begin{array}{l}\text { Average branch length } \\
(\mu \mathrm{m})\end{array}$ & $3.318 \pm 0.127$ & $3.218 \pm 0.075$ & $3.172 \pm 0.071$ & $3.237 \pm 0.041$ & $\begin{array}{l}\text { Sex } \times \text { diet, } 0.9630 \\
\text { Sex, } 0.5690 \\
\text { Diet, } 0.04635\end{array}$ & $\begin{array}{l}\text { Sex } \times \text { diet, } 0.3410 \\
\text { Sex, } 0.4616 \\
\text { Diet, } 0.8323\end{array}$ \\
\hline Longest branch $(\mu \mathrm{m})$ & $13.29 \pm 0.24$ & $13.26 \pm 0.49$ & $12.77 \pm 0.21$ & $13.99 \pm 0.21$ & $\begin{array}{l}\text { Sex } \times \text { diet, } 4.048 \\
\text { Sex, } 0.1145 \\
\text { Diet, } 3.750\end{array}$ & $\begin{array}{l}\text { Sex } \times \text { diet, } 0.0614 \\
\text { Sex, } 0.7395 \\
\text { Diet, } 0.0707\end{array}$ \\
\hline \# Junctions & $52.38 \pm 12.05$ & $53.49 \pm 7.28$ & $58.43 \pm 9.08$ & $52.28 \pm 6.78$ & $\begin{array}{l}\text { Sex } \times \text { diet, } 0.1616 \\
\text { Sex, } 0.07164 \\
\text { Diet, } 0.07779\end{array}$ & $\begin{array}{l}\text { Sex } \times \text { diet, } 0.6930 \\
\text { Sex, } 0.7924 \\
\text { Diet, } 0.7839\end{array}$ \\
\hline
\end{tabular}

\# number, \% percentage on total myeloid cells, a.u. arbitrary unit, CD control diet, mHFD maternal high-fat diet, $P$-values of significant statistical tests are in bold and followed by an asterisk indicating the significativity, ${ }^{*}<0.05$

stressed dark cells lastly displayed in the st lac mol similar numbers of lysosomes, lipofuscin, endosomes, and mitochondria, and their relationships with the microenvironment did not differ between groups.

\section{Discussion}

Our study investigated the effects of a fat enriched maternal diet on peripheral immune and microglial properties in the adolescent offspring of each sex. Characterization of our mouse model revealed a MIA phenotype defined by elevated circulating IL- 6 in the mothers, together with increased fat deposition in the mothers and male offspring without other major metabolic changes. This MIA model led to peripheral immune priming demonstrated by exacerbated release of IL- 6 upon an LPS-induced immune challenge in mHFD-exposed male and female offspring. The
mHFD-induced MIA resulted in significant microglial morphological changes in the dorsal hippocampus CA1. We also found sexually dimorphic hippocampal transcriptomic changes, with mHFD-exposed male offspring showing reduced mRNA expression of the inflammatory-regulating mediators $N f k b$ and $T g f 1 b$, and microglial receptors Tmem119, Trem2, and Cx3cr1. In parallel to these changes, mHFD-exposed male offspring had increased microglial interactions with astrocytes in the dorsal hippocampus CA1, while both mHFD males and females had decreased microglia-associated extracellular space pockets in the same region. Taken together, this data highlights the emergence of a partially sex-dependent priming that lasted until adolescence in the mHFD offspring.

Previous works studying the metabolic consequences of mHFD in rodents have reported variable effects. With 
Table 5 mHFD effects on microglial morphological parameters in the dorsal hippocampus CA1 stratum lacunosum moleculare of PND30 offspring

\begin{tabular}{|c|c|c|c|c|c|c|}
\hline \multirow[t]{3}{*}{ Parameters } & \multicolumn{4}{|c|}{ Mean \pm standard error of the mean } & \multirow[t]{3}{*}{$F$} & \multirow[t]{3}{*}{$p$} \\
\hline & \multicolumn{2}{|l|}{ Male } & \multicolumn{2}{|l|}{ Female } & & \\
\hline & $\mathrm{CD}$ & mHFD & $\mathrm{CD}$ & mHFD & & \\
\hline Soma area $\left(\mu m^{2}\right)$ & $40.18 \pm 1.74$ & $42.45 \pm 2.06$ & $40.14 \pm 0.92$ & $40.64 \pm 1.57$ & $\begin{array}{l}\text { Sex } \times \text { diet, } 0.2961 \\
\text { Sex, } 0.3230 \\
\text { Diet, } 0.7283\end{array}$ & $\begin{array}{l}\text { Sex } \times \text { diet, } 0.5938 \\
\text { Sex, } 0.5777 \\
\text { Diet, } 0.4060\end{array}$ \\
\hline Arbor area $\left(\mu m^{2}\right)$ & $988.76 \pm 125.44$ & $908.98 \pm 111.46$ & $974.04 \pm 118.48$ & $973.34 \pm 157.09$ & $\begin{array}{l}\text { Sex } \times \text { diet, } 0.09350 \\
\text { Sex, } 0.03685 \\
\text { Diet, } 0.09685\end{array}$ & $\begin{array}{l}\text { Sex } \times \text { diet, } 0.7637 \\
\text { Sex, } 0.8502 \\
\text { Diet, } 0.7597\end{array}$ \\
\hline Morphological index (a.u.) & $0.043 \pm 0.004$ & $0.049 \pm 0.005$ & $0.044 \pm 0.006$ & $0.047 \pm 0.009$ & $\begin{array}{l}\text { Sex } \times \text { diet, } 0.04385 \\
\text { Sex, } 7.575 \times 10^{-5} \\
\text { Diet, } 0.5447\end{array}$ & $\begin{array}{l}\text { Sex } \times \text { diet, } 0.8368 \\
\text { Sex, } 0.9932 \\
\text { Diet, } 0.4712\end{array}$ \\
\hline Cell area $\left(\mu m^{2}\right)$ & $272.57 \pm 46.35$ & $272.50 \pm 36.57$ & $269.99 \pm 40.25$ & $283.11 \pm 43.67$ & $\begin{array}{l}\text { Sex } \times \text { diet, } 0.02479 \\
\text { Sex, } 0.009177 \\
\text { Diet, } 0.02427\end{array}$ & $\begin{array}{l}\text { Sex } \times \text { diet, } 0.8769 \\
\text { Sex, } 0.9249 \\
\text { Diet, } 0.8782\end{array}$ \\
\hline Circularity (a.u.) & $0.028 \pm 0.003$ & $0.033 \pm 0.003$ & $0.031 \pm 0.003$ & $0.032 \pm 0.006$ & $\begin{array}{l}\text { Sex } \times \text { diet, } 0.2333 \\
\text { Sex, } 0.1162 \\
\text { Diet, } 0.6419\end{array}$ & $\begin{array}{l}\text { Sex } \times \text { diet, } 0.6357 \\
\text { Sex, } 0.7377 \\
\text { Diet, } 0.4348\end{array}$ \\
\hline Solidity (a.u.) & $0.258 \pm 0.012$ & $0.287 \pm 0.008$ & $0.263 \pm 0.007$ & $0.282 \pm 0.013$ & $\begin{array}{l}\text { Sex } \times \text { diet, } 0.2641 \\
\text { Sex, } 0.004823 \\
\text { Diet, } 5.616\end{array}$ & $\begin{array}{l}\text { Sex } \times \text { diet, } 0.6144 \\
\text { Sex, } 0.9455 \\
\text { Diet, } \mathbf{0 . 0 3 0 7 *}^{*}\end{array}$ \\
\hline Aspect ratio (a.u.) & $1.803 \pm 0.089$ & $1.787 \pm 0.058$ & $1.793 \pm 0.078$ & $1.752 \pm 0.094$ & $\begin{array}{l}\text { Sex } \times \text { diet, } 0.02490 \\
\text { Sex, } 0.07486 \\
\text { Diet, } 0.1260\end{array}$ & $\begin{array}{l}\text { Sex } \times \text { diet, } 0.8766 \\
\text { Sex, } 0.7879 \\
\text { Diet, } 0.7273\end{array}$ \\
\hline \# Branches & $72.83 \pm 12.86$ & $73.24 \pm 9.70$ & $73.90 \pm 11.91$ & $77.18 \pm 12.65$ & $\begin{array}{l}\text { Sex } \times \text { diet, } 0.01466 \\
\text { Sex, } 0.04465 \\
\text { Diet, } 0.02438\end{array}$ & $\begin{array}{l}\text { Sex } \times \text { diet, } 0.9052 \\
\text { Sex, } 0.8353 \\
\text { Diet, } 0.8779\end{array}$ \\
\hline Average branch length $(\mu \mathrm{m})$ & $3.464 \pm 0.077$ & $3.262 \pm 0.048$ & $3.420 \pm 0.120$ & $3.291 \pm 0.037$ & $\begin{array}{l}\text { Sex } \times \text { diet, } 0.2168 \\
\text { Sex, } 0.008423 \\
\text { Diet, } 4.553\end{array}$ & $\begin{array}{l}\text { Sex } \times \text { diet, } 0.6477 \\
\text { Sex, } 0.9280 \\
\text { Diet, } \mathbf{0 . 0 4 8 7 *}^{*}\end{array}$ \\
\hline Longest branch $(\mu \mathrm{m})$ & $13.61 \pm 0.46$ & $12.51 \pm 0.55$ & $12.96 \pm 0.57$ & $12.98 \pm 0.61$ & $\begin{array}{l}\text { Sex } \times \text { diet, } 1.024 \\
\text { Sex, } 0.02989 \\
\text { Diet, } 0.9634\end{array}$ & $\begin{array}{l}\text { Sex } \times \text { diet, } 0.3265 \\
\text { Sex, } 0.8649 \\
\text { Diet, } 0.3409\end{array}$ \\
\hline \# Junctions & $36.88 \pm 6.99$ & $37.01 \pm 5.19$ & $37.61 \pm 6.37$ & $39.29 \pm 6.71$ & $\begin{array}{l}\text { Sex } \times \text { diet, } 0.01468 \\
\text { Sex, } 0.05614 \\
\text { Diet, } 0.02034\end{array}$ & $\begin{array}{l}\text { Sex } \times \text { diet, } 0.9051 \\
\text { Sex, } 0.8157 \\
\text { Diet, } 0.8884\end{array}$ \\
\hline
\end{tabular}

\# number, \% percentage on total myeloid cells, a.u. arbitrary unit, $C D$ control diet, $m H F D$ maternal high-fat diet, $P$-values of significant statistical tests are in bold and followed by an asterisk indicating the significativity, ${ }^{*}<0.05$

the same diet protocol that we used but in rats, Sasaki et al. observed that weight differences varied with the age of the offspring across their lifespan upon exposure to mHFD [13, 32]. mHFD offspring were significantly heavier during pubertal stages (PND8 to PND21) [13], while at adolescence (PND35) [32] and adulthood (PND90), their weight was similar to control animals [13]. Similarly, we did not find any significant difference of body weight in the PND30 adolescent mouse offspring. By contrast, during early postnatal ages (PND1 to PND10), rat offspring exposed to lower fat mHFD (43\% kcal/fat vs our $60 \% \mathrm{kcal} /$ fat) became heavier with an increased fat mass [89], similar to our increased fat mass of mHFD-exposed male offspring. However, our P30 mHFD offspring showed no change in body weight that could be compensated notably by loss or change in composition of bone density, which has been previously observed after exposure to mHFD [90-92]. Future investigation using bone densitometry analysis could determine if that is also the case in our mHFD mouse model. The study also reported heavier dams with lower blood glucose levels prior to mating [89], describing a dietinduced obesity model. Bilbo and Tsang compared two types of mHFD in rats-one with saturated fat and the other with trans-fat-with the same protocol duration used here and found that both diets led to heavier dams [8]. In offspring, exposure to mHFD rich in saturated fats, and not trans-fats, led to significant weight grain in both sexes at puberty (PND20) and in males at adulthood (PND60) [8]. Also in rats, maternal programming after a HFD increased offspring body weight later in adulthood ( $>6$ weeks of age), whereas offspring exposed to a maternal high-sugar-fat diet were transiently lighter in early adulthood (4-5 weeks of age) [93]. In this latter 


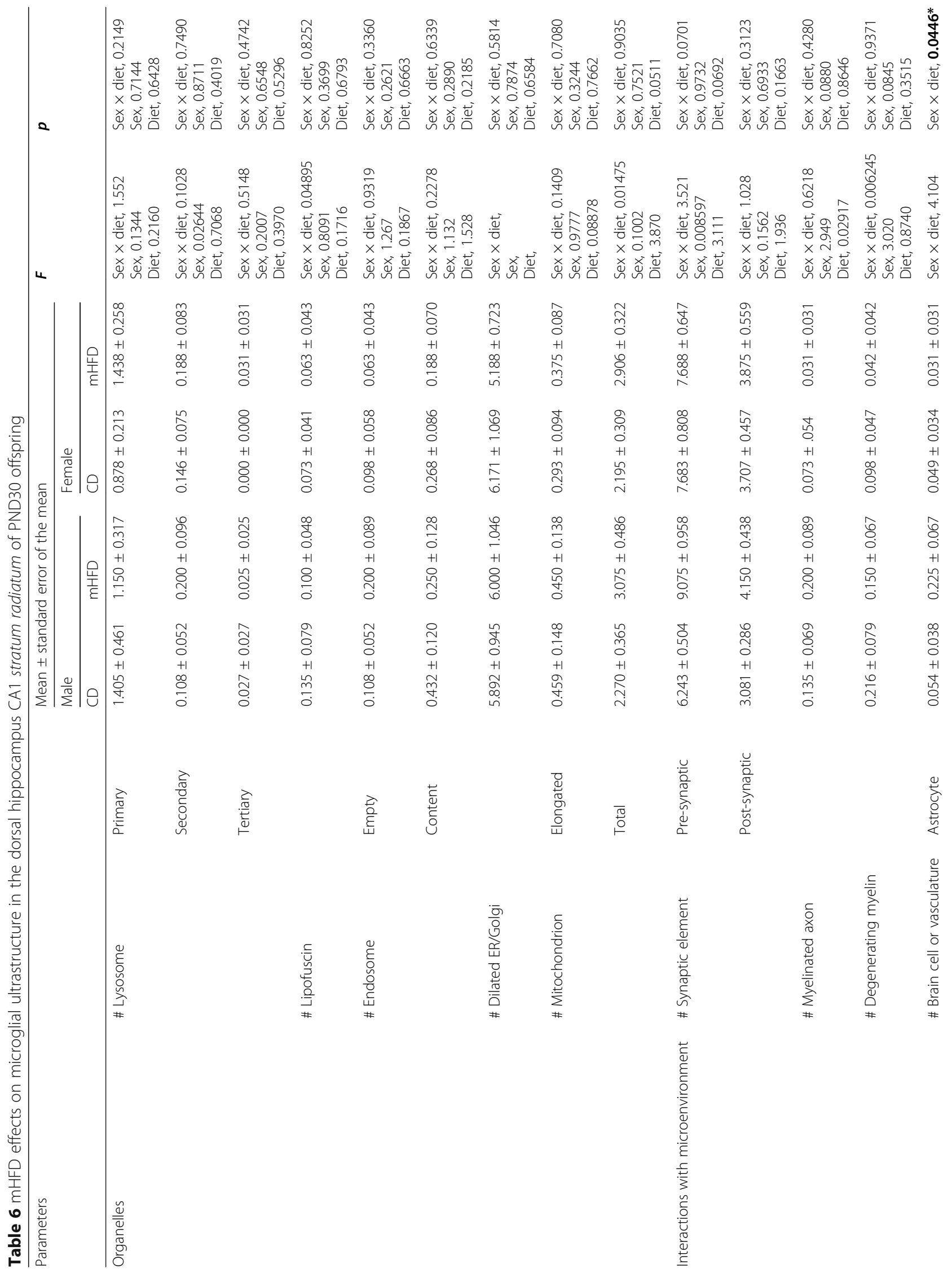




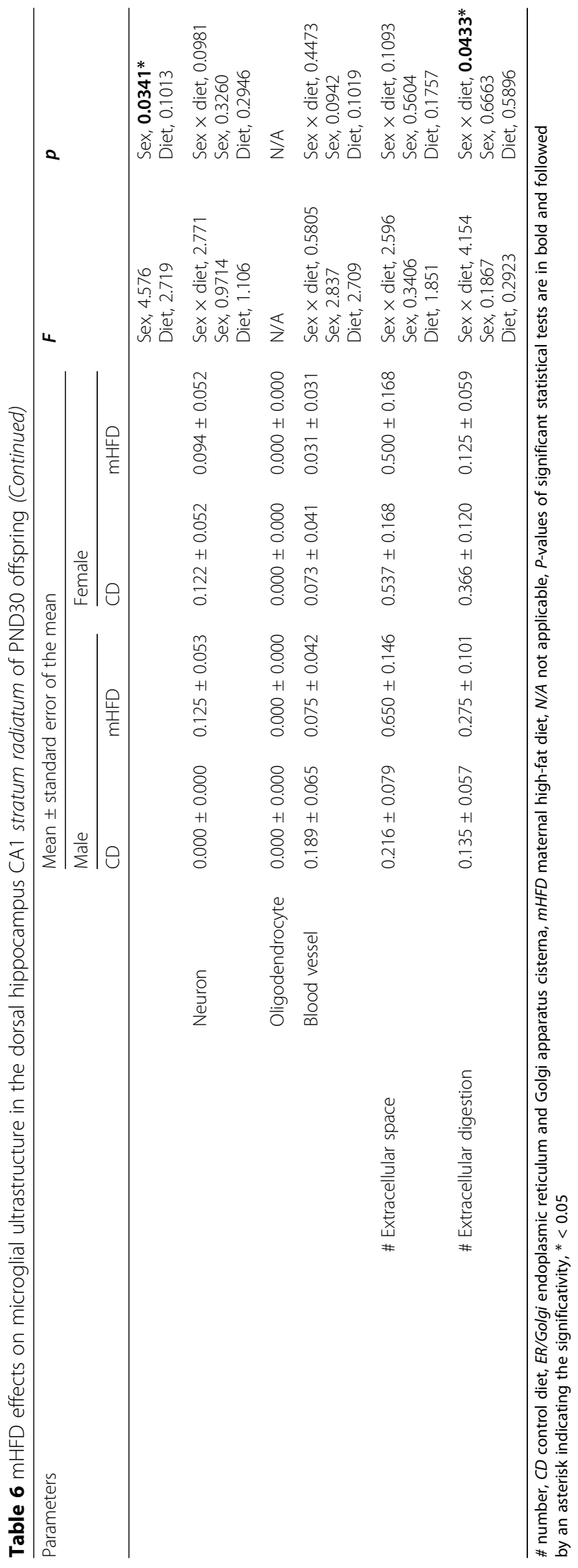



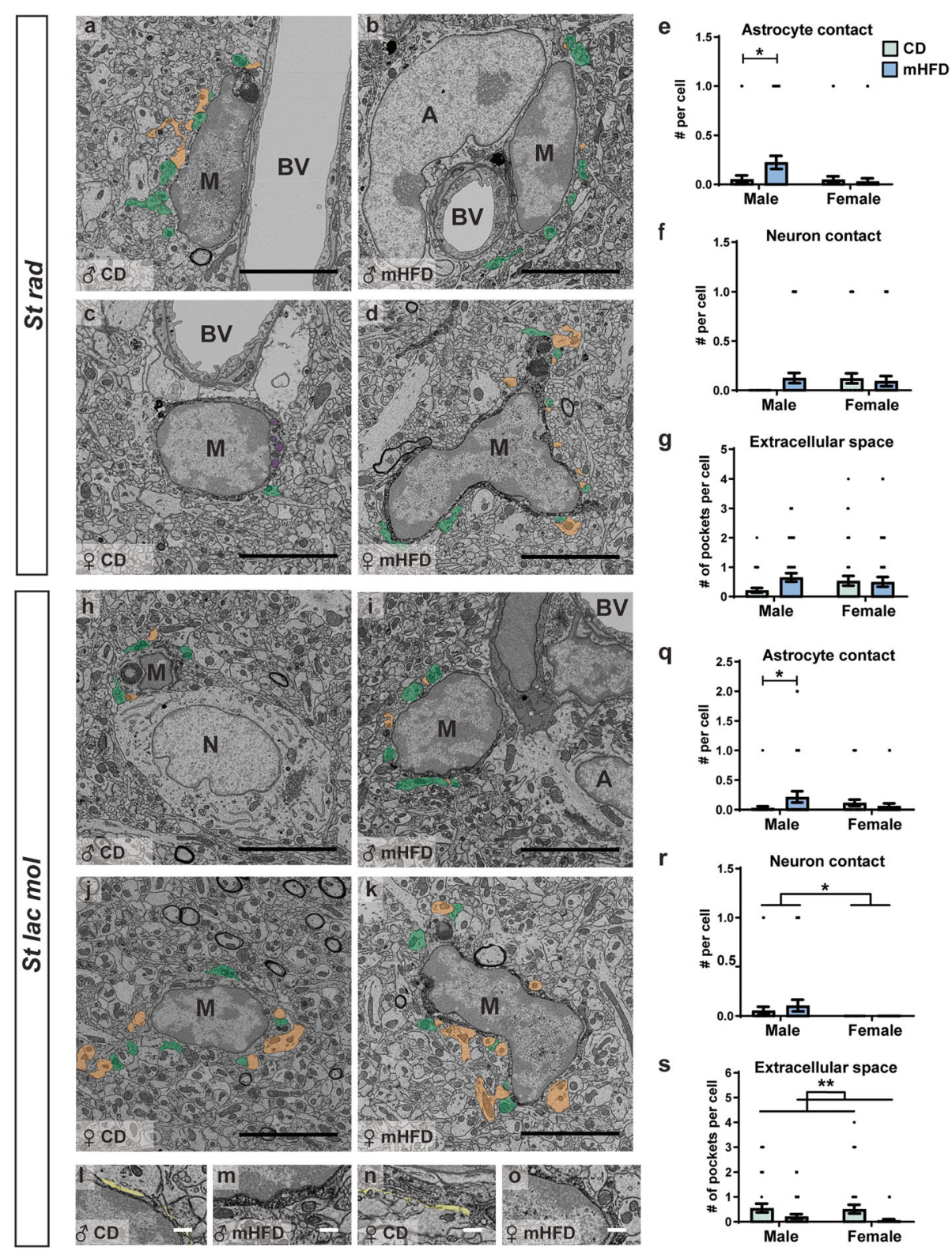

$\mathbf{q}$
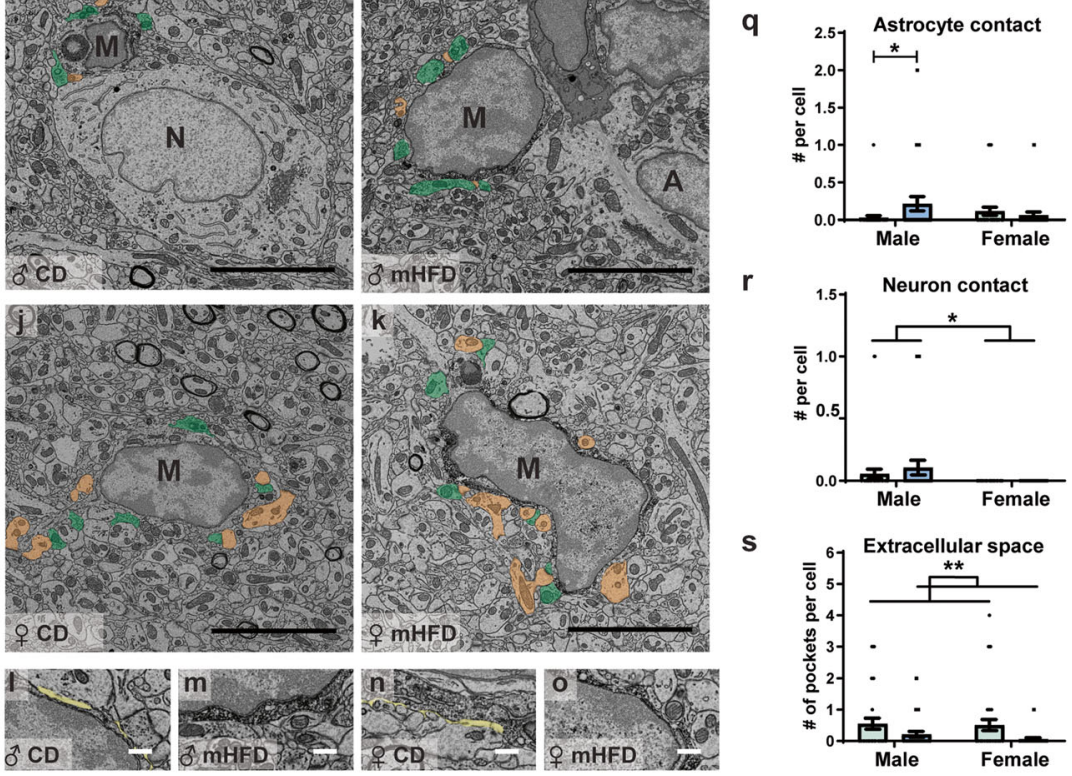

$\mathbf{r}$

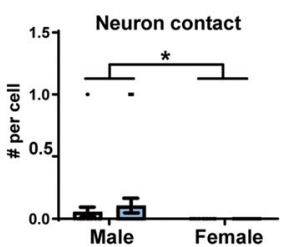

s

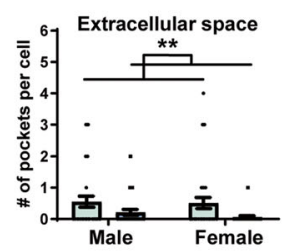

Fig. 6 mHFD effect on microglial ultrastructure in the dorsal hippocampus CA1 of PND30 offspring. Ultrastructural analysis of microglia was performed in the $\mathbf{a}-\mathbf{g}$ st rad and $\mathbf{h}-\mathbf{s}$ st lac mol. $\mathbf{a}-\mathbf{d}, \mathbf{h}-\mathbf{k}$ Representative pictures of microglia as well as $\mathbf{I}-\mathbf{o}$ higher magnification views of extracellular space pockets are provided. The interactions of microglia with their microenvironment differed between groups; here, we present main results for microglial contacts with $\mathbf{e}$, $\mathbf{q}$ astrocytes; $\mathbf{f}$, $\mathbf{r}$ neurons; and $\mathbf{g}, \mathbf{s}$ extracellular space pockets. On the representative pictures, astrocytes, blood vessels, microglia, and neurons are respectively identified by an "A," by "BV," by an " $M$," and by an "N." Presynaptic and postsynaptic elements are pseudo-colored respectively in green and orange. Mitochondria are pseudo-colored in purple and extracellular space pockets in yellow. Data are shown as mean \pm standard error of the mean. $p<0.05^{*}$ (sex) by 2 -way ANOVA, $p<0.05^{\#}$ (sex $\times$ diet) by 2 -way ANOVA followed by Bonferroni post-hoc test. + , female; $\partial$, male; CD, control; mHFD, maternal high-fat diet

study, dams fed with a HFD (45\% kcal/fat) did not present any weight gain, while dams fed with highsugar-fat diet weighed lower during gestation [93]. Overall, these studies suggest that the diet composition and exposure time may differently impact on the dams and offspring metabolism and that there might be slight differences between species (e.g., mouse vs rat). In comparison, our mHFD mouse model did not result in severe endocrinological alterations (i.e., obese or diabetic-like phenotype) in the dams, suggesting that the effects observed in our offspring were primarily due to the immunologic consequences of a fat enriched diet during pregnancy and nurturing, without confounding effects of obesity-induced metabolic dysregulation. 


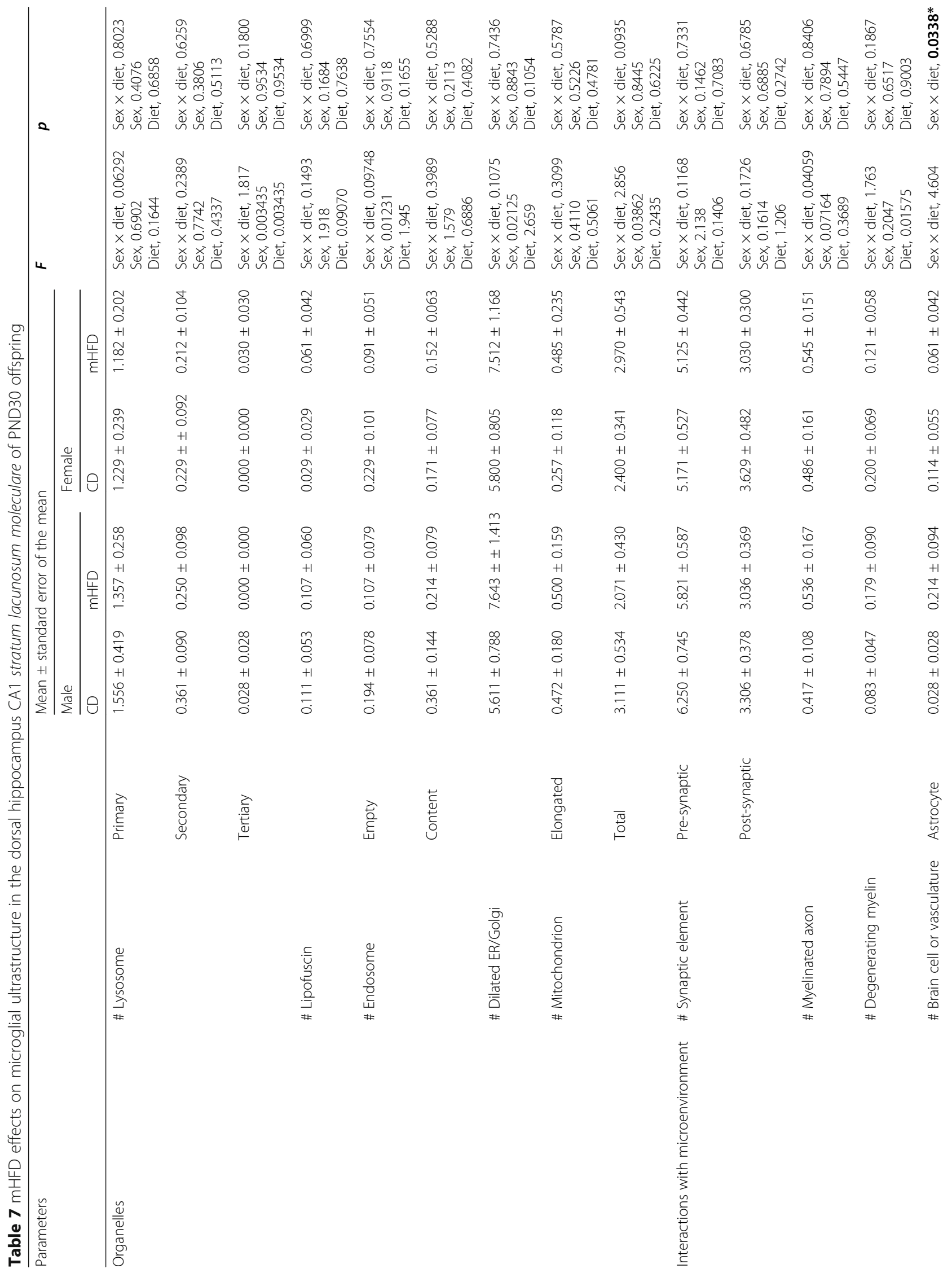




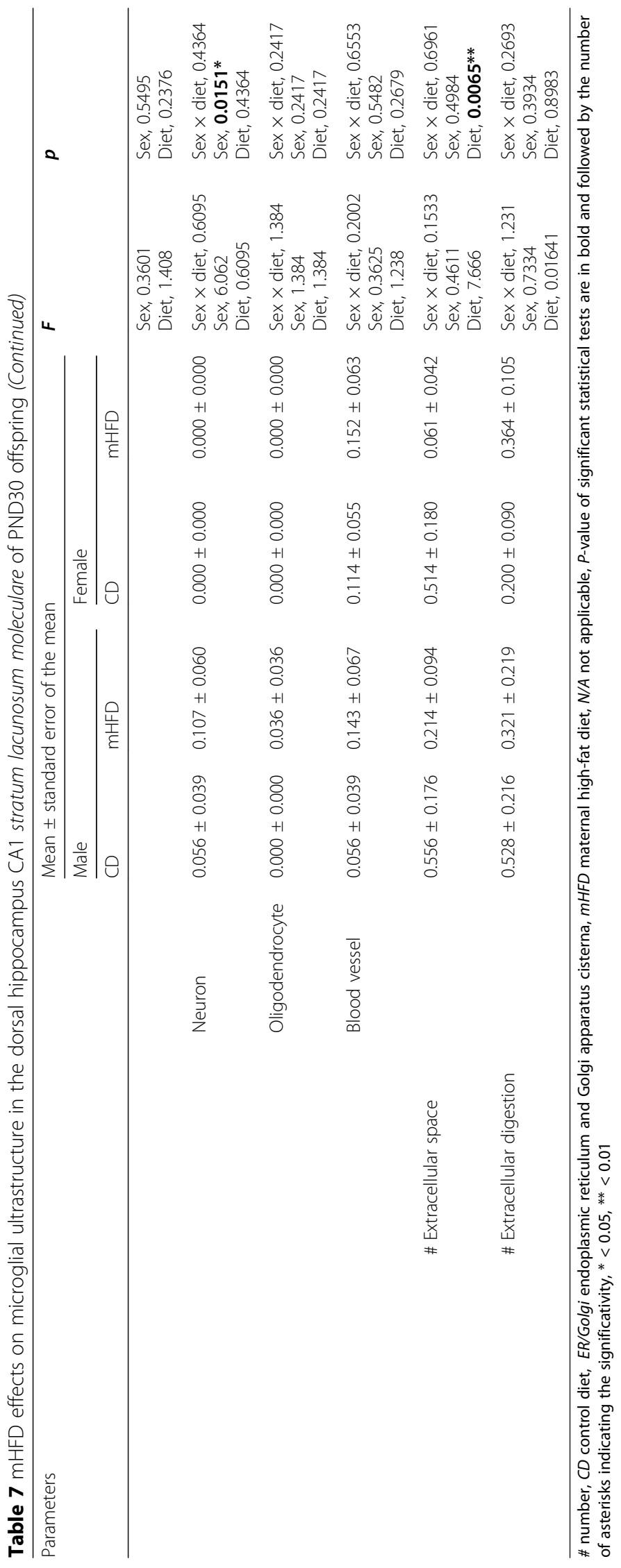



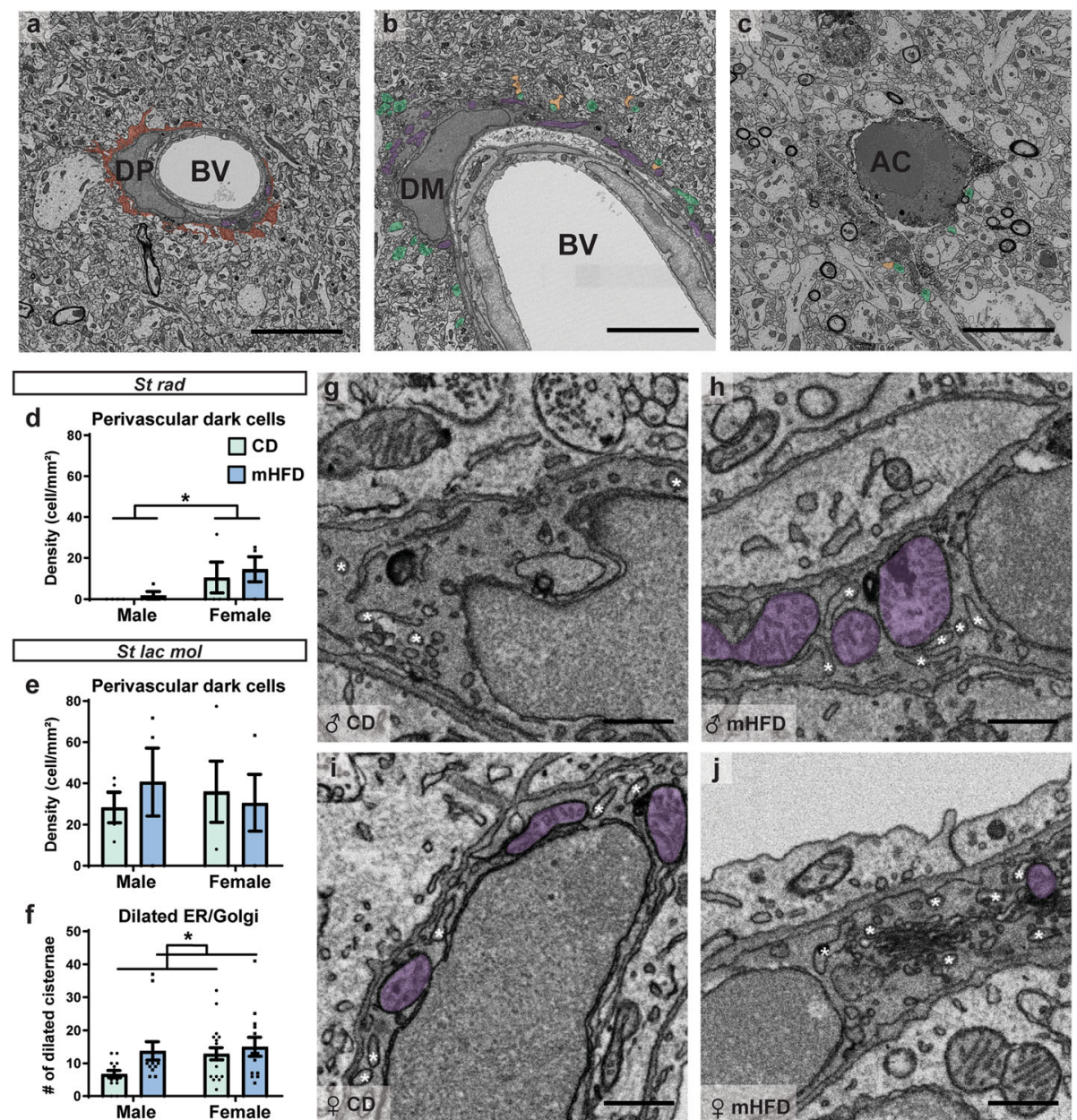

Fig. 7 mHFD effect on dark perivascular cells, dark microglial cells, and apoptotic cells in dorsal hippocampus CA1 of PND30 offspring. a Dark perivascular cells, $\mathbf{b}$ dark microglia, and $\mathbf{c}$ apoptotic cells examples are presented. Dark perivascular cell density was counted in the $\mathbf{d}$ st rad and the e st lac mol. Ultrastructural analysis of dark cells in the st lac mol revealed differences in their $\mathbf{f}-\mathbf{j}$ dilation of the endoplasmic reticulum and Golgi apparatus cisternae. Dark processes are pseudo-colored in red. Presynaptic and postsynaptic elements are pseudo-colored respectively in green and orange. Mitochondria are pseudo-colored in purple. Blood vessels are identified by "BV." Dark perivascular cell, dark microglia, and apoptotic cell are respectively identified using "DP," "DM," and "AC." Dilated endoplasmic reticulum and Golgi apparatus are identified by a white asterisk. Scale bar for representative picture of cell type is equivalent to $5 \mu \mathrm{m}$ while scale bar for picture showing endoplasmic reticulum and Golgi apparatus is equivalent to $500 \mathrm{~nm}$. Data are shown as mean \pm standard error of the mean. $p<0.05^{*}$ (sex) by 2 -way ANOVA, $p<0.05^{\#}$ (sex $\times$ diet) by 2-way ANOVA followed by Bonferroni post-hoc test. + , female; $\widehat{O}$, male; CD, control; Dilated ER/Golgi, dilated endoplasmic reticulum and Golgi apparatus cisternae; mHFD, maternal high-fat diet

Few studies have examined the MIA induced by mHFD as well as the mechanisms underlying these MIA effects of mHFD. Using a macaque model of mHFD, Thompson et al. have noted an elevation of the proinflammatory cytokine IL-12 and a decrease of macrophage-derived chemokine (also known as C-C motif chemokine 22) in the blood of the mothers [9]. This study was the first to directly highlight the interplay among metabolic and inflammatory maternal changes resulting from the diet and their consequences on the offspring behaviors. In rodents, Bilbo and Tsang did not observe an increase in IL-6 in rat dams fed with a high saturated fat diet [8], contrary to our study. However, subsequent studies using a mouse model as well as a more sensitive approach involving multiplex-ELISA observed increased levels of circulating cytokines, including IL-6, in dams, during pregnancy [75] and the end of nurturing [14]. Discrepancy between Bilbo and Tsang with ours' and others' results may be explained by the difference in the sensitivity between the techniques. In addition, differences between the diets or species used could also underlie this discrepancy. Interestingly, pregnant female rat fed with a HFD had increased mRNA levels of Il-6 in the placenta [75], suggesting that IL-6 could cross the placental barrier to modulate fetal development [94] in our model. 
In the mHFD-exposed offspring, alterations of the inflammatory status have notably been highlighted by increased cytokines levels (i.e., IL-5) in the blood of male mice at PND7 and of female mice at PND21 [14]. Moreover, another independent study has reported increased peripheral IL-6 $4 \mathrm{~h}$ after an LPS immune challenge in adult rat male and female offspring [8]. In agreement with our results, these data suggest that during both adolescence and adulthood, mHFD-exposed offspring have a stronger response to a systemic immune challenge. IL-6 could contribute to inducing immune programming changes in the offspring by modifying transcriptional regulation of inflammatory mediators that are part of IL- 6 downstream signaling target (i.e., $A P 1, N F \kappa B, S p 1)$ [76]. It is also possible that a stronger response to immune challenge occurs through increased release of cytokines by fat deposits. In the homeostatic central nervous system, Bilbo and Tsang reported an increase of protein levels of IL-1 $\beta$ without change of mRNA levels of $I l-1 \beta$ and $I l-6$ in PND20 pubertal and PND60 adult offspring, from both sexes [8]. Another group, Sasaki et al., revealed greater mRNA levels of $I l-6$ in the adolescent hippocampus [32] and no difference compared to control in the adult hippocampus [13] using a similar diet protocol in male and female rats. In the present study, we did not detect $\mathrm{Il}-1 \quad \beta$ or $\mathrm{Il}-6$ mRNA, suggesting levels below threshold for detection by rt-qPCR or a lower efficiency of the primers used. Although Sasaki et al. focused on an adolescent timepoint, they looked later, at PND45, and in rats. Therefore, further investigations are necessary to appraise the adolescence immune changes in mHFD rodent models.

In parallel to the changes of pro-inflammatory genes, neuroendocrine regulator genes (i.e., $G r, M r, N f k b$ ) were also reported to be differently expressed in the rat hippocampus across adolescence and adulthood [13, 32, 95]. These neuroendocrine receptors can modulate microglial functions such as their release of inflammatory mediators (i.e., IL-1 $\beta$, IL-6, TNF- $\alpha$ ) during an LPS immune challenge [96-98], their morphology [99], cellular dynamics, and proliferation [98]. Moreover, neuroendocrine receptors are differently expressed by microglia between the sexes [100]. In the current study, we found increased expression of Cox 2 and $N f k b 8 \mathrm{~h}$ after LPS; however, these genes were similarly increased regardless of the maternal diet. In homeostatic condition, we observed a sexual dimorphism of the transcription factor $N f k b$ and the homeostaticregulating cytokine $T g f b 1$, with lower expression levels detected in whole hippocampus of mHFD-exposed male offspring compared to other offspring groups. Decrease of $N f k b$ in SAL-treated animal suggests changes in its homeostatic functions, encompassing homeostatic regulation of neuronal excitability that may contribute to behavioral impairments [77]. Moreover, decrease of Tgfb1 expression indicates a loss of microglial homeostatic signature, which could affect their physiological functions and suggest a priming mechanism induced by mHFD. These transcriptional changes may be linked to aberrant behavioral outcomes. However, we cannot conclude from our present work on a direct relationship considering that the behavioral alterations were similar between sexes.

mHFD studies have mainly examined its effects on global inflammation and gene expression changes, without focusing on microglia. However, microglia may represent one of the key actors mediating the pathological consequences of mHFD during neurodevelopment. Bilbo and Tsang previously reported higher density of $\mathrm{IBA} 1^{+}$ cells in the hippocampus CA1, CA3, and dentate gyrus of mHFD-exposed male and female rat offspring at adulthood [8]. Similar effect of $\mathrm{IBA}^{+}{ }^{+}$increase has also been recently reported in the hypothalamus of rat offspring exposed to a maternal overnutrition model (highsugar-fat) [45]. In the present study, we did not observe any change in microglial density in the st rad and st lac mol of the dorsal hippocampus CA1. This could be explained by the method of analysis where microglia are identified by integrated density of $\mathrm{IBA} 1^{+}$staining among hippocampal regions (CA1, CA3, dentate gyrus) vs count of $\mathrm{IBA}^{+} / \mathrm{TMEM} 19^{+}$cells in individual CA1 layers, together with the age or the species of animals used. Nevertheless, we observed microglial morphological changes in the st rad (circularity) and in st lac mol (solidity), as well as a decreased average branch length in the st lac mol. The reduced microglial circularity in the st rad of mHFD-exposed offspring suggests that these cells took a more elongated shape. Microglia with an elongated, rod-like morphology have been previously proposed to play a role in the response to acute brain insults due to their increased prevalence [101]. Elongated bipolar microglia were also previously described in a viral MIA model, in which ex vivo analyses revealed that microglial chemotaxis and phagocytosis are increased in response to treatment (chemotaxis: CCL-2, IL-8, phagocytosis: LPS, poly I:C) [102]. The increased microglial solidity may represent a change in the distribution of the arborization, particularly a decreased distance between branches which would reflect a more convex-like shape. Others also hypothesized that an increase of the solidity value occurs during the morphological shift from a ramified to an amoeboid shape upon neuroinflammatory insults and represents a de-ramified or bushy morphology [103, 104], a phenotype seen upon exposure to stress [105]. In a bacterial MIA mouse model, microglia were previously shown to shift their morphology to an ameboid shape in adolescent (PND40) offspring amygdala [106]. Although the microglial morphological changes we observed varied between layers, similarly they could indicate a general shift from a surveillant-ramified state to an amoeboid 
shape. This morphological shift may also accompany microglial functional alterations in the hippocampus CA1 of mHFD offspring.

Microglia from the mHFD vs CD offspring interacted differently with their microenvironment. In st lac mol, the presence of extracellular space pockets surrounding microglial cell bodies decreased, which could be explained for instance by changes in the composition of the extracellular matrix [107]. Microglia themselves contribute to modifying the extracellular matrix by releasing cathepsins, heparinases, and metalloproteinases [108, 109] that promote their cell body migration and process motility, notably during inflammation $[108,109]$, as well as experience-dependent plasticity during normal physiological conditions [36, 110]. Hence, the reduction in microglia-associated extracellular space that we measured could indicate a decrease in microglial dynamics associated with impaired physiological functions.

Together with the decreased expression of microglial receptors (i.e., Cx3cr1, Tmem119, Trem2), the morphological and functional changes that we observed could be partially caused by the transcriptomic alterations in adolescent male offspring. Although its role remains under investigation, TMEM119 is constitutively and exclusively expressed by microglia [55] and is required for their survival [81]. However, the absence of changes in the microglial and infiltrating myeloid cells population size suggest no major issue with microglia survival, without excluding the possibility of a change in the turnover of the population. Similar to TMEM119, TREM2 aids microglia to survive, in addition to mediating physiological functions that include blood flow regulation [111], phagocytosis, and synaptic pruning [82, 85-87]. CX3CR1 is also involved in microglial phagocytosis and synaptic remodeling [83, 84, 112]. Hence, a decrease of Cx3cr 1 and Trem 2 mRNA expression may reflect reduced microglial interactions with neurons or synaptic elements as well as phagocytic activities, which was not observed at the ultrastructural level. It should be noted however that our ultrastructural analysis focused on microglial cell bodies, leaving the possibility that microglial processes make less contacts with synapses, which remains to be explored. A recent study suggested that microglial TREM2 may be involved in the mediation of microglia-astrocyte crosstalk. Using a TREM2 knockout mouse model, TREM2 deficiency led to a lack of microglia-astrocyte interactions in the cerebral cortex and hippocampus, which prevented the astrocytic-mediated phagocytosis of axon terminals [113]. The decrease of TREM2 that we observed may represent a partial loss of microglial control over this newly defined function of astrocytes at synapses. Taken with the ultrastructural finding of male-specific increase of microglial interactions with astrocytes, these results stress the importance of determining the molecular crosstalk between microglia and astrocytes that is at play in mHFD-exposed male offspring. Interestingly, investigating epigenetic changes of the oxytocin receptor in the hippocampus of mHFDexposed male and female mouse offspring by chromatin immunoprecipitation-qPCR revealed a sexually dimorphic pattern of acetylation and methylation leading to an increased expression of the oxytocin receptor in the hippocampus of male offspring only [114]. Further investigation looking at whole genome epigenomic changes could hence provide, in parallel with post-translational modifications and/or protein expression analysis, better understanding of how microglial function differs between sexes upon mHFD.

Our laboratory has previously identified dark microglia as a subset of microglia associated with pathological conditions that are characterized by a dark cytoplasm and nucleoplasm without a clear chromatin pattern [54, 69]. Not only microglia can undertake a "dark" appearance but several other types of brain cells such as neurons, oligodendrocytes $[58,66]$, and astrocytes $[115,116]$ as well. Here, we not only observed dark microglia but also stressed dark perivascular cells showing several signs of cellular stress (i.e., elongated mitochondria and dilated cisternae of the endoplasmic reticulum and Golgi apparatus) and dying apoptotic cells sometimes immunopositive for IBA1 in the dorsal hippocampus CA1 of the PND30 offspring. No difference in the density of stressed dark cells and apoptotic cells was observed with the maternal diet. However, an interesting observation we made was the increased density of stressed dark perivascular cells in the st rad of female offspring compared to male offspring from both maternal diets. Unfortunately, the low sample size of stressed dark cells and apoptotic cells did not allow us to perform quantitative analysis in the dorsal hippocampus CA1 st rad. Similar to previous observations by our team in adult pathological conditions, dark microglia were mainly found to be located in the st lac mol among the CA1 [69]. We thus assessed the global changes in stressed dark cells organelles without discriminating dark microglia from dark perivascular cells to increase our sample size. This analysis of dark microglia and dark perivascular cells revealed a significantly increased number of dilated endoplasmic reticulum and Golgi apparatus cisternae. Dilation of the endoplasmic reticulum and the Golgi apparatus are well characterized ultrastructural signs of oxidative stress [117]. The increase in their incidence thus reflects a higher level of cellular stress in the dorsal hippocampus CA1 of mHFD-exposed adolescent offspring. It would be interesting to investigate the cellular stress signature of the two cell types at the molecular level and the effects of dark microglia as well as dark perivascular cells on the blood-brain barrier. In fact, increased stress within 
the neurovascular unit could alter blood-brain barrier integrity and permeability, as well as the regulation of blood flow. Consequently, a dysfunctional blood-brain barrier may leak into the brain peripheral inflammatory signals released upon mHFD, such as IL-6, thus contributing to the microglial changes observed.

\section{Conclusion}

Although mHFD induced similar phenotypes in both sexes for IL-6-driven immune priming and microglial morphology, we identified sex-specific effects in the mHFD male offspring in terms of transcriptomic (Nfkk, Tgflb, Tmem119, Trem2, Cx3cr1) as well as ultrastructural (astrocyte-microglia interaction) changes during adolescence. Considering their key role in shaping brain neuronal networks, microglia in dorsal hippocampus may be partially responsible for several pathological neurodevelopmental outcomes described in mHFD models. Adolescence is a period of intense brain plasticity and maturation, where several microglia-mediated processes, such as synaptic pruning and myelination, are ongoing and may be profoundly impacted by the mHFD-driven microglial priming. Notably, synaptic pruning may be especially impacted negatively in mHFD-exposed male offspring. Investigation into these specific neurodevelopmental processes across the brain and determining the kinetics of their alterations during the offspring neurodevelopment, from embryonic stages to young adulthood, will be central to understanding the sexually dimorphic pathological cascade involving microglia as well as microglia-astrocyte crosstalk.

\section{Supplementary information}

Supplementary information accompanies this paper at https://doi.org/10. 1186/s12974-020-01914-1.

\section{Additional file 1:. Supplementary methods [118] \\ Additional file 2: Supplementary Figure 1. Weight, weight gain, food, and calories follow-up throughout diet protocol on the dams.}

Additional file 3: Supplementary Figure 2. HFD effect on blood glucose, fat deposition, gestation duration and litter size.

Additional file 4: Supplementary Figure 3. mHFD effect on fat deposition in the PND30 offspring.

Additional file 5: Supplementary Table 1. mHFD effects on the density of dark microglia, dark perivascular cells, and apoptotic cells in the dorsal hippocampus CA1 stratum radiatum and stratum lacunosum moleculare of PND30 offspring.

Additional file 6: Supplementary Table 2. mHFD effects on the ultrastructure of dark cells in the dorsal hippocampus CA1 stratum radiatum of PND30 offspring.

Additional file 7: Supplementary Table 3. mHFD effects on the ultrastructure of dark cells in the stratum lacunosum moleculare of the dorsal hippocampus CA1 of PND30 offspring.

\section{Abbreviations}

AP-1: Activator protein-1; Aif1: Allograft inflammatory factor 1; a.u.: Arbitrary units; ANOVA: Analysis of variance; CA: Cornu ammonis; CD: Control chow; CDNA: Complementary deoxyribonucleic acid; Cox2: Cyclooxygenase 2; $\mathrm{Ct}$ : Cycle threshold; x3cr1: Fractalkine receptor; DAB: Diaminobenzidine;
ED: Embryonic day; ELISA: Enzyme-linked immunosorbent assay; Gapdh: Glyceraldehyde 3-phosphate dehydrogenase; HFD: High-fat diet; IBA1: Ionized calcium-binding adapter 1; IL: Interleukin; II1ra: IL1 receptor antagonist; IKB: Nfkb inhibitor; LPS: Lipopolysaccharide; mHFD: Maternal HFD; MIA: Maternal immune activation; MKP-1: Mitogen-activated kinase protein 1; mRNA: Messenger RNA; Nfkb: Nuclear factor k-light-chain-enhancer activator of B cells; PND: Postnatal day; PB: Phosphate buffer; PBS: Phosphate buffered saline; PFA: Paraformaldehyde; RNA: Ribonucleic acid; RPL32: Ribosomal protein L32; rt-qPCR: Real-time quantitative polymerase chain reaction; SAL: Saline; SEM: Scanning electron microscopy; Sp-1: Specificity protein 1; St lac mol: Stratum lacunosum moleculare; St rad: Stratum radiatum; TBS: Tris buffered saline; Tgf1 $\beta$ R: Transforming growth factor beta 1 receptor; TMEM119: Transmembrane protein 119; TNF: Tumor necrosis factor; Trem2: Triggering receptor expressed on myeloid cells 2; W: Week

\section{Acknowledgements}

We are grateful to Julie-Christine Lévesque for providing training and support at the Bioimaging platform of the Infectious Disease Research Center funded by the Canadian Foundation Innovation (CFI), Dr. Emmanuel Planel for the access to epifluorescence microscope, and Dr. Sebastien Hébert for the access to rt-qPCR apparatus. Warm thank to Katherine Picard and MarieKim St-Pierre who performed the confocal imaging for the morphological analyses of microglia. We are thankful to their positive energy and support throughout this study. We also thank Iris Kim and Kasia J. Szyszkowicz for technical support. Finally, we are thankful to Giamal N. Luheshi for help providing animals and support with the first part of these experiments and Mallar Chakravarty for his guidance and support towards the end of the study.

\section{Authors' contributions}

$\mathrm{MB}$ designed the initial experiments and coordinated most of the experiments. CL and NV helped with the optimization of RNA isolation, and NV gave precious guidance for rt-qPCR design and taught MB electron microscopy tissue processing. JCS helped with experimental design for ultrastructural imaging and analysis using SEM. MET provided constructive insights into experimental design and data interpretation throughout the study.

MB performed and analyzed all the physiological follow-ups of the pregnant mothers and offspring as well as multiplex-ELISA on the mothers. MB mainly performed tissue processing and all data analyses. CL and LFC assisted with part of the animal care, the sacrifice of the offspring and performed multiplex-ELISA experiments on the offspring. CL and LFC discussed possible avenue to better answer the experimental questions of this study. JCS and FGl provided their expertise and imaged for ultrastructural analysis using SEM.

$\mathrm{MB}$ mainly wrote the manuscript under guidance from MET. All authors read, edited, and approved the final manuscript.

\section{Funding}

This research was supported by an NSERC Discovery grant awarded to MET (\#RGPIN-2014-05308). MB is a holder of the FRQS doctoral award. During the study, CL received the Returning student award from the Integrated Program in Neuroscience of McGill University, and LFC held the Vanier Canada Graduate scholarship. JCS received the FRQS postdoctoral fellowship. $\mathrm{FGl}$ is a holder of a full doctoral scholarship from CONTACYT, Mexican Council of Science and Technology. MET is a Canada Research Chair (Tier II) in Neurobiology of Aging and Cognition.

\section{Availability of data and materials}

The data that support the findings of this study are available from the corresponding author, MET, upon reasonable request.

\section{Ethics approval and consent to participate}

All animal protocols were approved by McGill's Facility Animal Care Committee under the ethical guidelines of the Canadian Council on Animal Care.

\section{Consent for publication}

Not applicable 


\section{Author details}

'Integrated Program in Neuroscience, McGill University, Montreal, QC, Canada. ${ }^{2}$ Axe neurosciences, Centre de recherche du CHU de QuébecUniversité Laval, Québec, QC, Canada. ${ }^{3}$ Cerebral Imaging Center, Douglas Mental Health University Institute, McGill University, Montréal, QC, Canada. ${ }^{4}$ Department of Neurosciences, University of California, La Jolla, San Diego, CA, USA. ${ }^{5}$ Département de médecine moléculaire, Université Laval, Québec, QC, Canada. ${ }^{6}$ Department of Neurology and Neurosurgery, McGill University, Montréal, QC, Canada. ${ }^{7}$ Division of Medical Sciences, University of Victoria, Victoria, BC, Canada. ${ }^{8}$ Department of Biochemistry and Molecular Biology, University of British Columbia, Vancouver, BC, Canada.

\section{Received: 28 April 2020 Accepted: 29 July 2020}

Published online: 05 September 2020

\section{References}

1. Bolton JL, Bilbo SD. Developmental programming of brain and behavior by perinatal diet: focus on inflammatory mechanisms. Dialogues Clin Neurosci. 2014;16:307-20.

2. Sullivan EL, Riper KM, Lockard R, Valleau JC. Maternal high-fat diet programming of the neuroendocrine system and behavior. Horm Behav. 2015;76:153-61.

3. Mina TH, Lahti M, Drake AJ, Räikkönen K, Minnis H, Denison FC, et al. Prenatal exposure to very severe maternal obesity is associated with adverse neuropsychiatric outcomes in children. Psychol Med. 2017;47:35362.

4. Chen C, Xu X, Yan Y. Estimated global overweight and obesity burden in pregnant women based on panel data model. PLoS One. 2018;13:e0202183.

5. Bleich SN, Cutler D, Murray C, Adams A. Why is the developed world obese? Annu Rev Public Health. 2008:29:273-95.

6. Hariri N, Thibault L. High-fat diet-induced obesity in animal models. Nutr Res Rev. 2010;23:270-99.

7. Sauerwald TU, Demmelmair H, Koletzko B. Polyunsaturated fatty acid supply with human milk. Lipids. 2001;36:991-6.

8. Bilbo SD, Tsang V. Enduring consequences of maternal obesity for brain inflammation and behavior of offspring. FASEB J. 2010;24:2104-15.

9. Thompson JR, Gustafsson HC, DeCapo M, Takahashi DL, Bagley JL, Dean TA, et al. Maternal diet, metabolic state, and inflammatory response exert unique and long-lasting influences on offspring behavior in non-human primates. Front Endocrinol. 2018;9:161.

10. Winther G, Elfving B, Müller HK, Lund S, Wegener G. Maternal high-fat diet programs offspring emotional behavior in adulthood. Neuroscience. 2018; 388:87-101.

11. Sullivan EL, Grayson B, Takahashi D, Robertson N, Maier A, Bethea CL, et al. Chronic consumption of a high-fat diet during pregnancy causes perturbations in the serotonergic system and increased anxiety-like behavior in nonhuman primate offspring. J Neurosci. 2010;30:3826-30.

12. Peleg-Raibstein D, Luca E, Wolfrum C. Maternal high-fat diet in mice programs emotional behavior in adulthood. Behav Brain Res. 2012;233:398404.

13. Sasaki A, de Vega WC, St-Cyr S, Pan P, McGowan PO. Perinatal high fat diet alters glucocorticoid signaling and anxiety behavior in adulthood. Neuroscience. 2013;240:1-12.

14. Graf AE, Lallier SW, Waidyaratne G, Thompson MD, Tipple TE, Hester ME, et al. Maternal high fat diet exposure is associated with increased hepcidin levels, decreased myelination, and neurobehavioral changes in male offspring. Brain Behav Immun. 2016:58:369-78.

15. Cordner ZA, Khambadkone SG, Boersma GJ, Song L, Summers TN, Moran $\mathrm{TH}$, et al. Maternal high-fat diet results in cognitive impairment and hippocampal gene expression changes in rat offspring. Exp Neurol. 2019; 318:92.

16. Tozuka Y, Kumon M, Wada E, Onodera M, Mochizuki H, Wada K. Maternal obesity impairs hippocampal BDNF production and spatial learning performance in young mouse offspring. Neurochem Int. 2010;57:235-47.

17. Grissom NM, Herdt CT, Desilets J, Lidsky-Everson J, Reyes TM. Dissociable deficits of executive function caused by gestational adversity are linked to specific transcriptional changes in the prefrontal cortex. Neuropsychopharmacology. 2015;40:1353-63.

18. Smith BL, Laaker CJ, Lloyd KR, Hiltz AR, Reyes TM. Adolescent microglia play a role in executive function in male mice exposed to perinatal high fat diet. Brain Behav Immun. 2019;84:80-9.
19. Meyer U, Feldon J, Fatemi SH. In-vivo rodent models for the experimental investigation of prenatal immune activation effects in neurodevelopmental brain disorders. Neurosci Biobehav Rev. 2009;33:1061-79.

20. Estes ML, McAllister AK. Maternal immune activation: implications for neuropsychiatric disorders. Science. 2016;353:772-7.

21. Brucato M, Ladd-Acosta C, Li M, Caruso D, Hong X, Kaczaniuk J, et al. Prenatal exposure to fever is associated with autism spectrum disorder in the Boston birth cohort. Autism Res Off J Int Soc Autism Res. 2017;10:187890.

22. Bilbo SD, Block CL, Bolton JL, Hanamsagar R, Tran PK. Beyond infection maternal immune activation by environmental factors, microglial development, and relevance for autism spectrum disorders. Exp Neurol. 2018:299:241-51.

23. Feigenson KA, Kusnecov AW, Silverstein SM. Inflammation and the two-hit hypothesis of schizophrenia. Neurosci Biobehav Rev. 2014;38:72-93.

24. Delpech J-C, Wei L, Hao J, Yu X, Madore C, Butovsky O, et al. Early life stress perturbs the maturation of microglia in the developing hippocampus. Brain Behav Immun. 2016;57:79-93.

25. Rincel M, Lépinay AL, Janthakhin Y, Soudain G, Yvon S, Silva SD, et al. Maternal high-fat diet and early life stress differentially modulate spine density and dendritic morphology in the medial prefrontal cortex of juvenile and adult rats. Brain Struct Funct. 2017:1-13.

26. Huizink AC, Mulder EJH. Maternal smoking, drinking or cannabis use during pregnancy and neurobehavioral and cognitive functioning in human offspring. Neurosci Biobehav Rev. 2006;30:24-41.

27. Proietti E, Röösli M, Frey U, Latzin P. Air pollution during pregnancy and neonatal outcome: a review. J Aerosol Med Pulm Drug Deliv. 2012;26:9-23.

28. Bolton IL, Auten RL, Bilbo SD. Prenatal air pollution exposure induces sexually dimorphic fetal programming of metabolic and neuroinflammatory outcomes in adult offspring. Brain Behav Immun. 2014;37:30-44.

29. Knuesel I, Chicha L, Britschgi M, Schobel SA, Bodmer M, Hellings JA, et al. Maternal immune activation and abnormal brain development across CNS disorders. Nat Rev Neurol. 2014;10:643-60.

30. Trépanier MO, Hopperton KE, Mizrahi R, Mechawar N, Bazinet RP. Postmortem evidence of cerebral inflammation in schizophrenia: a systematic review. Mol Psychiatry. 2016;21:1009-26.

31. van Kesteren CFMG, Gremmels H, de Witte LD, Hol EM, Van Gool AR, Falkai $P G$, et al. Immune involvement in the pathogenesis of schizophrenia: a meta-analysis on postmortem brain studies. Transl Psychiatry. 2017;7:e1075.

32. Sasaki A, de Vega W, Sivanathan S, St-Cyr S, McGowan PO. Maternal high-fat diet alters anxiety behavior and glucocorticoid signaling in adolescent offspring. Neuroscience. 2014;272:92-101.

33. Schwarz JM, Bilbo SD. Sex, glia, and development: interactions in health and disease. Horm Behav. 2012;62:243-53.

34. Hanamsagar R, Bilbo SD. Sex differences in neurodevelopmental and neurodegenerative disorders: focus on microglial function and neuroinflammation during development. J Steroid Biochem Mol Biol. 2016; 160:127-33.

35. Bordeleau M, Carrier M, Luheshi GN, Tremblay M-Ė. Microglia along sex lines: from brain colonization, maturation and function, to implication in neurodevelopmental disorders. Semin Cell Dev Biol. 2019;94:152-63.

36. Tremblay M-Ë, Lowery RL, Majewska AK. Microglial interactions with synapses are modulated by visual experience. PLoS Biol. 2010;8:e1000527.

37. Domingues HS, Portugal CC, Socodato R, Relvas JB. Oligodendrocyte, astrocyte, and microglia crosstalk in myelin development, damage, and repair. Front Cell Dev Biol. 2016;4:71.

38. Kaur C, Rathnasamy G, Ling E-A. Biology of microglia in the developing brain. J Neuropathol Exp Neurol. 2017;76:736-53.

39. Paolicelli RC, Ferretti MT. Function and dysfunction of microglia during brain development: consequences for synapses and neural circuits. Front Synaptic Neurosci. 2017:9:9.

40. Hatanaka Y, Wada K, Kabuta T. Maternal high-fat diet leads to persistent synaptic instability in mouse offspring via oxidative stress during lactation. Neurochem Int. 2016;97:99-108.

41. Paradis J, Boureau P, Moyon T, Nicklaus S, Parnet P, Paillé V. Perinatal Western diet consumption leads to profound plasticity and GABAergic phenotype changes within hypothalamus and reward pathway from birth to sexual maturity in rat. Front Endocrinol. 2017;8:216.

42. Janthakhin $Y$, Rincel M, Costa A-M, Darnaudéry M, Ferreira G. Maternal highfat diet leads to hippocampal and amygdala dendritic remodeling in adult male offspring. Psychoneuroendocrinology. 2017;83:49-57. 
43. Norden DM, Muccigrosso MM, Godbout JP. Microglial priming and enhanced reactivity to secondary insult in aging, and traumatic CNS injury, and neurodegenerative disease. Neuropharmacology. 2015;96:29-41.

44. Bilbo SD, Schwarz JM. Early-life programming of later-life brain and behavior: a critical role for the immune system. Front Behav Neurosci. 2009;3:14.

45. Maldonado-Ruiz R, Cárdenas-Tueme M, Montalvo-Martínez L, Vidaltamayo R, Garza-Ocañas L, Reséndez-Perez D, et al. Priming of hypothalamic ghrelin signaling and microglia activation exacerbate feeding in rats' offspring following maternal overnutrition. Nutrients. 2019:11:1241

46. Yoon T, Okada J, Jung MW, Kim JJ. Prefrontal cortex and hippocampus subserve different components of working memory in rats. Learn Mem. 2008;15:97-105.

47. Lee A-R, Kim J-H, Cho E, Kim M, Park M. Dorsal and ventral hippocampus differentiate in functional pathways and differentially associate with neurological disease-related genes during postnatal development. Front Mol Neurosci. 2017;10:331.

48. McHugh SB, Campbell TG, Taylor AM, Rawlins JNP, Bannerman DM. A role for dorsal and ventral hippocampus in inter-temporal choice cost-benefit decision making. Behav Neurosci. 2008;122:1-8.

49. Spear LP. The adolescent brain and age-related behavioral manifestations. Neurosci Biobehav Rev. 2000:24:417-63.

50. Utsuyama M, Hirokawa K. Differential expression of various cytokine receptors in the brain after stimulation with LPS in young and old mice. Exp Gerontol. 2002;37:411-20.

51. Skelly DT, Hennessy E, Dansereau M-A, Cunningham C. A systematic analysis of the peripheral and CNS effects of systemic LPS, IL-1B, TNF- $a$ and IL-6 challenges in C57BL/6 mice. PLoS One. 2013;8:e69123.

52. Gálvez-Peralta M, Wang Z, Bao S, Knoell DL, Nebert DW. Tissue-specific induction of mouse ZIP8 and ZIP14 divalent cation/bicarbonate symporters by, and cytokine response to, inflammatory signals: Int J Toxicol. SAGE PublicationsSage CA: Los Angeles. CA. 2014;33:246-58.

53. Everhardt Queen A, Moerdyk-Schauwecker M, McKee LM, Leamy LJ, Huet YM. Differential expression of inflammatory cytokines and stress genes in male and female mice in response to a lipopolysaccharide challenge. PLoS One. 2016;11:e0152289.

54. Hui CW, St-Pierre A, El Hajj H, Remy Y, Hébert SS, Luheshi GN, et al. Prenatal immune challenge in mice leads to partly sex-dependent behavioral, microglial, and molecular abnormalities associated with schizophrenia. Front Mol Neurosci. 2018;11:13.

55. Bennett ML, Bennett FC, Liddelow SA, Ajami B, Zamanian JL, Fernhoff NB, et al. New tools for studying microglia in the mouse and human CNS. Proc Natl Acad Sci U S A. 2016;113:E1738-46.

56. Ibanez González F, Picard K, Bordelau M, Sharma K, Bisht K, Tremblay M-Ė. Immunofluorescence staining using IBA1 and TMEM119 for microglial density, morphology and peripheral myeloid cell infiltration analysis in mouse brain. J Vis Exp. 2019. https://doi.org/10.3791/60510.

57. Paxinos G, Franklin KBJ. Paxinos and Franklin's the mouse brain in stereotaxic coordinates. 4th ed. Amsterdam: Elsevier/Academic Press; 2013

58. Tremblay M-Ë, Zettel ML, Ison JR, Allen PD, Majewska AK. Effects of aging and sensory loss on glial cells in mouse visual and auditory cortices. Glia. 2012;60:541-58

59. Young K, Morrison H. Quantifying microglia morphology from photomicrographs of immunohistochemistry prepared tissue using ImageJ. J Vis Exp. 2018. https://doi.org/10.3791/57648.

60. St-Pierre M-K, Bordeleau M, Tremblay M-È. Visualizing dark microglia. Microglia. New York, NY: Humana; 2019. p. 97-110.

61. Hajj HE, Savage JC, Bisht K, Parent M, Vallières L, Rivest $S$, et al. Ultrastructural evidence of microglial heterogeneity in Alzheimer's disease amyloid pathology. J Neuroinflammation. 2019;16:87.

62. Chavez-Valdez R, Flock DL, Martin LJ, Northington FJ. Endoplasmic reticulum pathology and stress response in neurons precede programmed necrosis after neonatal hypoxia-ischemia. Int J Dev Neurosci Off J Int Soc Dev Neurosci. 2016;48:58

63. De Duve C. The lysosome. Sci Am. 1963;208:64-72.

64. Holtzman E, Novikoff AB, Villaverde H. Lysosomes and Gerl in normal and chromatolytic of the rat ganglion nodosum. J Cell Biol. 1967;33:419-35.

65. Nandy K. Properties of neuronal lipofuscin pigment in mice. Acta Neuropathol (Berl). 1971;19:25-32.

66. Peters A, Palay SL, Webster H deF. The fine structure of the nervous system. Neurons and their Supporting Cells. 3rd edition. J Neuropathol Exp Neurol. 1991;50:282-282
67. Maxfield FR, Barbosa-Lorenzi VC, Singh RK. Digestive exophagy: phagocyte digestion of objects too large for phagocytosis. Traffic. 2020;21:6-12.

68. Haka AS, Barbosa-Lorenzi VC, Lee HJ, Falcone DJ, Hudis CA, Dannenberg AJ, et al. Exocytosis of macrophage lysosomes leads to digestion of apoptotic adipocytes and foam cell formation. J Lipid Res. 2016;57:980-92.

69. Bisht K, Sharma KP, Lecours C, Gabriela Sánchez M, El Hajj H, Milior G, et al. Dark microglia: a new phenotype predominantly associated with pathological states. Glia. 2016;64:826-39.

70. Zhang J, Reedy MC, Hannun YA, Obeid LM. Inhibition of caspases inhibits the release of apoptotic bodies: $\mathrm{BCl}-2$ inhibits the initiation of formation of apoptotic bodies in chemotherapeutic agent-induced apoptosis. J Cell Biol. 1999;145:99-108.

71. Faul F, Erdfelder E, Lang A-G, Buchner A. G*power 3: a flexible statistical power analysis program for the social, behavioral, and biomedical sciences. Behav Res Methods. 2007:39:175-91.

72. Ohta T, Toriniwa Y, Ryumon N, Inaba N, Hirao T, Yamanaka S, et al. Maternal high-fat diet promotes onset of diabetes in rat offspring. Anim Sci J. 2017; 88:149-55.

73. Hohos NM, Skaznik-Wikiel ME. High-fat diet and female fertility. Endocrinology. 2017;158:2407-19.

74. Castanon N, Luheshi G, Layé S. Role of neuroinflammation in the emotional and cognitive alterations displayed by animal models of obesity. Front Neurosci. 2015:9:229.

75. Kretschmer T, Schulze-Edinghausen M, Turnwald E-M, Janoschek R, BaeGartz I, Zentis P, et al. Effect of maternal obesity in mice on IL-6 levels and placental endothelial cell homeostasis. Nutrients. 2020;12:296.

76. Luo Y, Zheng SG. Hall of fame among pro-inflammatory cytokines: interleukin- 6 gene and its transcriptional regulation mechanisms. Front Immunol. Frontiers. 2016;7:604.

77. Dresselhaus EC, Meffert MK. Cellular specificity of NF-KB function in the nervous system. Front Immunol. Frontiers. 2019;10:1043.

78. Niraula A, Sheridan JF, Godbout JP. Microglia priming with aging and stress. Neuropsychopharmacology. 2017;42:318-33

79. Butovsky O, Jedrychowski MP, Moore CS, Cialic R, Lanser AJ, Gabriely G, et al. Identification of a unique TGF- $\beta$ dependent molecular and functional signature in microglia. Nat Neurosci. 2014;17:131-43.

80. Kishikawa S, Sato S, Kaneto S, Uchino S, Kohsaka S, Nakamura S, et al. Allograft inflammatory factor 1 is a regulator of transcytosis in M cells. Nat Commun. 2017;8:1-10.

81. Zheng $H$, Jia L, Liu C-C, Rong Z, Zhong L, Yang L, et al. TREM2 promotes microglial survival by activating Wnt/ß-catenin pathway. J Neurosci. 2017:37:1772-84.

82. Filipello F, Morini R, Corradini I, Zerbi V, Canzi A, Michalski B, et al. The microglial innate immune receptor TREM2 is required for synapse elimination and normal brain connectivity. Immunity. 2018;48:979-991.e8.

83. Zhan Y, Paolicelli RC, Sforazzini F, Weinhard L, Bolasco G, Pagani F, et al. Deficient neuron-microglia signaling results in impaired functional brain connectivity and social behavior. Nat Neurosci. 2014;17:400-6.

84. Paolicelli RC, Bolasco G, Pagani F, Maggi L, Scianni M, Panzanelli P, et al. Synaptic pruning by microglia is necessary for normal brain development. Science. 2011;333:1456-8.

85. Kawabori M, Kacimi R, Kauppinen T, Calosing C, Kim JY, Hsieh CL, et al. Triggering receptor expressed on myeloid cells 2 (TREM2) deficiency attenuates phagocytic activities of microglia and exacerbates ischemic damage in experimental stroke. J Neurosci. 2015;35:3384-96.

86. Chertoff M, Shrivastava K, Gonzalez B, Acarin L, Giménez-Llort L. Differential modulation of TREM2 protein during postnatal brain development in mice. PLoS One. 2013;8:e72083.

87. Thrash JC, Torbett BE, Carson MJ. Developmental regulation of TREM2 and DAP12 expression in the murine CNS: implications for Nasu-Hakola disease. Neurochem Res. 2009:34:38-45.

88. Schaefers ATU, Grafen K, Teuchert-Noodt G, Winter Y. Synaptic remodeling in the dentate gyrus, CA3, CA1, subiculum, and entorhinal cortex of mice: effects of deprived rearing and voluntary running. Neural Plast. 2010;2010: 870573

89. Barrand S, Crowley TM, Wood-Bradley RJ, Jong KAD, Armitage JA. Impact of maternal high fat diet on hypothalamic transcriptome in neonatal Sprague Dawley rats. PLoS One. 2017;12:e0189492.

90. MacPherson REK, Castelli LM, Miotto PM, Frendo-Cumbo S, Milburn A, Roy $B D$, et al. A maternal high fat diet has long-lasting effects on skeletal muscle lipid and PLIN protein content in rat offspring at young adulthood. Lipids. 2015;50:205-17 
91. Lanham SA, Roberts C, Hollingworth T, Sreekumar R, Elahi MM, Cagampang FR, et al. Maternal high-fat diet: effects on offspring bone structure. Osteoporos Int. 2010;21:1703-14.

92. Chen J-R, Lazarenko OP, Zhao H, Alund AW, Shankar K. Maternal obesity impairs skeletal development in adult offspring. J Endocrinol. 2018;239:3347.

93. Cardenas-Perez RE, Fuentes-Mera L, de la Garza AL, Torre-Villalvazo I, Reyes Castro LA, Rodriguez-Rocha $\mathrm{H}$, et al. Maternal overnutrition by hypercaloric diets programs hypothalamic mitochondrial fusion and metabolic dysfunction in rat male offspring. Nutr Metab. 2018:15:38.

94. Dahlgren J, Samuelsson A-M, Jansson T, Holmäng A. Interleukin-6 in the maternal circulation reaches the rat fetus in mid-gestation. Pediatr Res. 2006;60:147-51.

95. Wijenayake S, Rahman MF, Lum CMW, De Vega WC, Sasaki A, McGowan PO. Maternal high-fat diet induces sex-specific changes to glucocorticoid and inflammatory signaling in response to corticosterone and lipopolysaccharide challenge in adult rat offspring. J Neuroinflammation. 2020;17:116

96. Barrientos RM, Thompson VM, Kitt MM, Amat J, Hale MW, Frank MG, et al. Greater glucocorticoid receptor activation in hippocampus of aged rats sensitizes microglia. Neurobiol Aging. 2015:36:1483-95.

97. Chantong B, Kratschmar DV, Nashev LG, Balazs Z, Odermatt A. Mineralocorticoid and glucocorticoid receptors differentially regulate NFkappaB activity and pro-inflammatory cytokine production in murine BV-2 microglial cells. J Neuroinflammation. 2012;9:260.

98. Carrillo-de Sauvage MÁ, Maatouk L, Arnoux I, Pasco M, Sanz Diez A, Delahaye $M$, et al. Potent and multiple regulatory actions of microglia glucocorticoid receptors during CNS inflammation. Cell Death Differ. 2013; 20:1546-57.

99. van Olst L, Bielefeld $\mathrm{P}$, Fitzsimons $\mathrm{CP}$, de Vries HE, Schouten $\mathrm{M}$. Glucocorticoid-mediated modulation of morphological changes associated with aging in microglia. Aging Cell. 2018;17:e12790

100. Villa A, Gelosa P, Castiglioni L, Cimino M, Rizzi N, Pepe G, et al. Sex-specific features of microglia from adult mice. Cell Rep. 2018;23:3501-11.

101. Taylor SE, Morganti-Kossmann C, Lifshitz J, Ziebell JM. Rod microglia: a morphological definition. PLOS ONE. Public Libr Sci; 2014;9:e97096.

102. Ji P, Schachtschneider KM, Schook LB, Walker FR, Johnson RW. Peripheral viral infection induced microglial sensome genes and enhanced microglial cell activity in the hippocampus of neonatal piglets. Brain Behav Immun. 2016:54:243-51.

103. del Mar Fernández-Arjona M, Grondona JM, Fernández-Llebrez P, LópezÁvalos MD. Microglial morphometric parameters correlate with the expression level of IL-1 $\beta$, and allow identifying different activated morphotypes. Front Cell Neurosci. 2019;13:472.

104. Zanier ER, Fumagalli S, Perego C, Pischiutta F, De Simoni M-G. Shape descriptors of the "never resting" microglia in three different acute brain injury models in mice. Intensive Care Med Exp. 2015:3:7.

105. Tay TL, Béchade C, D'Andrea I, St-Pierre M-K, Henry MS, Roumier A, et al. Microglia gone rogue: impacts on psychiatric disorders across the lifespan. Front Mol Neurosci. 2018;10:421.

106. O'Loughlin E, Pakan JMP, Yilmazer-Hanke D, McDermott KW. Acute in utero exposure to lipopolysaccharide induces inflammation in the pre- and postnatal brain and alters the glial cytoarchitecture in the developing amygdala. J Neuroinflammation. 2017;14:212.

107. Hrabetova S, Cognet L, Rusakov DA, Nägerl UV. Unveiling the extracellular space of the brain: from super-resolved microstructure to in vivo function. J Neurosci Soc Neuroscience. 2018;38:9355-63.

108. del Zoppo Gregory J. Milner Richard, Mabuchi Takuma, hung Stephanie, Wang Xiaoyun, berg Greta I., et al. microglial activation and matrix protease generation during focal cerebral ischemia. Stroke. 2007;38:646-51.

109. Lively S, Schlichter LC. The microglial activation state regulates migration and roles of matrix-dissolving enzymes for invasion. J Neuroinflammation. 2013;10:843

110. Tremblay M-Ë, Majewska AK. A role for microglia in synaptic plasticity? Commun Integr Biol. 2011;4:220-2.

111. Kleinberger G, Brendel M, Mracsko E, Wefers B, Groeneweg L, Xiang X, et al. The FTD-like syndrome causing TREM2 T66M mutation impairs microglia function, brain perfusion, and glucose metabolism. EMBO J. 2017;36:183753.

112. Noda M, Doi Y, Liang J Kawanokuchi J J Sonobe Y, Takeuchi H, et al. Fractalkine attenuates excito-neurotoxicity via microglial clearance of damaged neurons and antioxidant enzyme heme oxygenase-1 expression. J Biol Chem. 2011;286:2308-19.

113. Jay TR, von Saucken VE, Muñoz B, Codocedo JF, Atwood BK, Lamb BT, et al. TREM2 is required for microglial instruction of astrocytic synaptic engulfment in neurodevelopment. Glia. 2019;67:1873-92.

114. Glendining KA, Jasoni CL. Maternal high fat diet-induced obesity modifies histone binding and expression of oxtr in offspring hippocampus in a sexspecific manner. Int J Mol Sci. 2019;20:329.

115. Mori S, Leblond CP. Electron microscopic features and proliferation of astrocytes in the corpus callosum of the rat. J Comp Neurol. 1969;137:197225.

116. Castejón OJ. Astrocyte subtypes in the gray matter of injured human cerebral cortex: a transmission electron microscope study. Brain Inj. 1999;13: 291-304.

117. Schönthal $A H$. Endoplasmic reticulum stress: its role in disease and novel prospects for therapy. Scientifica. 2012;2012:857516.

118. Grant CW, Moran-Paul CM, Duclos SK, Guberski DL, Arreaza-Rubín G, Spain LM. Testing agents for prevention or reversal of type 1 diabetes in rodents. PLoS One. 2013;8:e72989.

\section{Publisher's Note}

Springer Nature remains neutral with regard to jurisdictional claims in published maps and institutional affiliations.
Ready to submit your research? Choose BMC and benefit from:

- fast, convenient online submission

- thorough peer review by experienced researchers in your field

- rapid publication on acceptance

- support for research data, including large and complex data types

- gold Open Access which fosters wider collaboration and increased citations

- maximum visibility for your research: over $100 \mathrm{M}$ website views per year

At $\mathrm{BMC}$, research is always in progress.

Learn more biomedcentral.com/submissions 